\title{
Matter of Agency: Active Materials in Digital Design Research
}

Digital design projects, once criticized for their lack of materiality, have within the last decade undergone a shift from issues of representation toward questions of material performance and manufacturing. Nurturing new relationships with disciplines such as physics, biology, engineering, and materials science, digital design fully participates in one of the defining trends of the current period: a radical redefining of our relationship with materiality, which has its origins in the growing proximity of computational and material issues. Recently, developments in digital design research have introduced a new set of conceptual and practical challenges into the field, which I propose to situate here in the interdisciplinary context of active matter. As a growing number of designers experiment with the production of emergent structures through bespoke fabrication processes, often involving 'noncalibrated' materials (such as clay and polymers), the dominant understanding of digital manufacturing - based on the idea of an identity of the digital model and its physical realization - is increasingly being called into question. In stark contrast with digital design's industrial beginnings, recent experiments hint toward a participatory understanding of digital production, in which the role of the designer shifts from top-down production of geometric models toward the preparation of a form of openness to active material behavior. This chapter aims to qualify this approach from both theoretical and empirical perspectives, arguing for its recognition as one of digital design's main contributions to the field of active matter, before the use of 'smart' and 'responsive' materials in design projects.

\section{Introduction}

Digital technologies, once envisioned as the agents of a radical, global dematerialization of our physical environment - an idea perhaps best captured in Nicholas Negroponte's 1995 essay, Being Digital [Negroponte 1995] - are today playing an ever-increasing role in the creation of new material structures and behaviors. Far from removing us from material concerns, computation - through its various manifestations, from simulation to

Acknowledgments: The author wishes to acknowledge Andrea Graziano, Marco Palma, Bruno Demasi, Alessio Erioli, and Olivier Dauchot for their collaboration in the projects discussed in this chapter, as well as the following institutions for their financial and material support: EnsadLab; PSL University; the Arts \& Sciences chair of the École polytechnique, EnsAD - PSL, and the Daniel \& Nina Carasso foundation; digifabTURINg. The author would also like to thank the editors for their fruitful comments and remarks on this chapter. 
manufacturing and assembly - has created new modes of interaction with the physical world, by putting complex material behavior within the reach of science, engineering, and design.

As a consequence of this global and interdisciplinary transformation of our relationship with materiality, the field of digital design ${ }^{1}$ is undergoing profound changes. From the mid-1990s, when critics voiced concerns about the lack of materiality in digital projects, ${ }^{2}$ to the developments of the last decade, digital design's trajectory reveals a clear inflexion from issues of representation toward questions of material performance and manufacturing. These transformations have resulted in the growing proximity of digital design to disciplines such as physics, biology, materials science, and engineering. The creation of new materials, from the tailoring of properties at the microscopic level to the packing of functional building blocks in so-called metamaterials [Kadic et al. 2013], whose properties go beyond what can be found in nature, has thus become a major topic of interest for some designers, as exemplified by the recent successes of initiatives such as MIT's Self-Assembly Lab and Tangible Media laboratories. But perhaps more strikingly, a global rethinking of the relationship to 'traditional' materials - such as clay, steel, timber, and concrete - has developed out of the bridging of computational design methods and digital fabrication processes. The recent works of architects Ronald Rael and Virginia San Fratello, ${ }^{3}$ designer Olivier van Herpt, ${ }^{4}$ artist Jonathan Keep, ${ }^{5}$ and designer collective Co-de-iT, ${ }^{6}$ among others, have for instance developed a new aesthetic language based on the emergent behavior of clay, in a process merging additive manufacturing, scripting, and the material's inner plasticity and tendency to buckling (Fig. 1).

The evolution of digital design research's experimental output, made more visible during the past 6 years, reveals an increased interest in the production of emergent

1 This chapter assumes an interdisciplinary position within the field of digital design research, acknowledging that today's context is more adequately defined by a fluid circulation of ideas, concepts, and workflows rather than by strict boundaries between disciplines. I shall therefore understand here the term 'design' in the broader sense of a process of 'conception,' rather than as referring to a specific practice (like architecture of industrial design) implementing such a process.

2 One can mention here, for instance, the critiques expressed by architectural theorist Kenneth Frampton in his 1995 Studies in Tectonic Culture concerning the recent tendency to the "dematerialization of building" [Frampton 1995, p. 381] observed in the architectural profession. Although Frampton describes a broader cultural phenomenon and does not explicitly target the influence of computers, his attempt to reassert the centrality of architecture's relationship with structure and construction - in an age where digital technologies began to infuse all aspects of life - has been discussed and criticized by early advocates of a 'virtual' architecture. On this matter, see for instance: [Mitchell 1998]. For a nuanced discussion of Kenneth [Frampton's viewpoint on computers within architecture, see: [Frampton, Allen, and Foster 2003, pp. 55-56].

3 https://www.rael-sanfratello.com/ (accessed November 4, 2019).

$4 \mathrm{http}: / /$ oliviervanherpt.com/ (accessed November 4, 2019).

5 http://www.keep-art.co.uk/ (accessed November 4, 2019).

6 http://www.co-de-it.com/ (accessed November 4, 2019). 


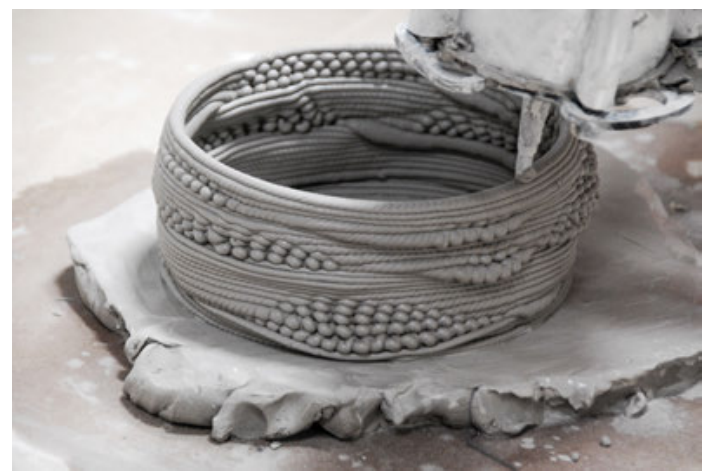

Fig. 1: A clay vessel robotically printed by Co-de-iT as part of the inFORMed matter research project. (๑) Bruno Demasi (reproduced with authorization).

material structures, whose qualities challenge the very assumption of an identity of digital form and its material realization. The parametrically modeled, smooth geometries that came to define the mid-1990s and early 2000s in digital architecture and product design, as exemplified by Greg Lynn's and Ross Lovegrove's works, ${ }^{7}$ have given way to a vocabulary of discreteness and discontinuity, fracture and roughness; the "pliant [and] supple" [Lynn 1993] geometries of the first digital age are today losing ground to highly textured formations, bearing the volatile marks of unpredictable material behavior.

Architecture schools, once at the forefront of the digitization and 'virtualization' of design practices (the earliest and most famous example being the Paperless Studio experiment, led at Columbia University in the mid-1990s under the supervision of Bernard Tschumi) are among the most prominent experimenters of this new relationship between form and matter in digital design: one can mention, for instance, the Bartlett School of Architecture's Design Computation Lab, ${ }^{8}$ as well as the Architectural Association's Design Research Lab, ${ }^{9}$ both based in London. Within these environments, bespoke digital fabrication processes, involving the emergent behavior of materials such as wax, ${ }^{10} \mathrm{ABS},{ }^{11}$ and polyurethane foam, ${ }^{12}$ are being experimented at the scale

7 See, for instance, Greg Lynn's tea and coffee service for Alessi (http://glform.com/shop/alessi-teacoffee-towers/, accessed August 16, 2018) or Ross Lovegrove's water bottle for Ty Nant (http://www. rosslovegrove.com/index.php/custom_type/ty-nant/, accessed August 16, 2018).

$8 \mathrm{https}$ //designcomputationlab.org/ (accessed November 4, 2019).

$9 \mathrm{http://drl.aaschool.ac.uk/} \mathrm{(accessed} \mathrm{November} \mathrm{4,} \mathrm{2019).}$

10 One can mention here the robotic wax deposition experiments led at the Southern California Institute of Architecture (SCI-Arc) by Brian Harms and Nicholas Barger: http://nstrmnt.com/\#/buoy ant-depositions (accessed November 2, 2019).

11 On the development of innovative 3D printing processes involving ABS plastics, see for instance the research developed at the Bartlett School of Architecture's Design Computation Lab: Retsin, Garcia 2016.

12 On the development of custom manufacturing processes involving polyurethane foam, see for instance: [Colletti 2013] . 
of architectural components or furniture. Firmly rooted in design research, these experiments coexist with more applied programs, which approach the development of new manufacturing processes through the creation of architecture-scale structures the most notable examples being the series of pavilions ${ }^{13}$ jointly built in Stuttgart by the Institute for Computational Design and Construction ${ }^{14}$ (ICD) and the Institute of Building Structures and Structural Design (ITKE). ${ }^{15}$

Beyond differences in aesthetics or purpose, these experiments share a common commitment to reinvesting the morphogenetic potential of active material behavior within contemporary digital design, a project sometimes linked to such historical precedents as Frei Otto's use of analog “form-finding” models [Menges 2015, p. 10]. Indeed, it is most often by abandoning the prospect of total digital control, and embracing the opportunities offered by "non-calibrated" materials [Morel 2014, p. 84], that today's designers are discovering new territories of aesthetics and structural performance. As a consequence, digital design workflows are increasingly moving toward a 'participatory' vision of production, in which the designer's authority and aesthetic intent is brought to a form of negotiation with active material processes.

This chapter intends to situate these recent developments of digital design research in the interdisciplinary context of active matter ${ }^{16}$ and highlight some potential specificities of design's contribution to this field. The relevance of the notion of active matter in design, as I shall argue here, does not materialize first in applications of 'smart' or responsive materials but rather in the growing adoption of design methods allowing for an openness to matter's “inherent capacity for the generation of form” [DeLanda 2002, p. 134] to be incorporated in the project itself.

The remainder of this chapter is divided into three sections. The next section analyzes the recent transformations of digital design workflows as a shift from a representational to a performative understanding of design, fostering the field's growing interest in active materials. Sections 3 and 4 then introduce two recently completed design experiments: Unspecified Clay, a retroactive production system focusing on emergent clay

13 See for instance [Doerstelmann et al. 2015].

14 https://icd.uni-stuttgart.de/ (accessed November 4, 2019).

15 https://www.itke.uni-stuttgart.de/ (accessed November 4, 2019).

16 The term 'active matter' should be understood here primarily in reference to the interdisciplinary research field developing within natural sciences for approximately the last 20 years which focuses on the emergence of collective motion in living or inert systems composed of multiple interacting entities such as a flock of birds, or a colloidal solution. For a general introduction to this field, see for instance: [Popkin 2016]. The Manoeuvres project, discussed in this chapter, directly relates to this field through its development in collaboration with active matter physicist Olivier Dauchot. This chapter will also discuss material systems (such as clay extrusions) that, while not falling strictly into the active matter field defined in the natural sciences, are investigated from a design point of view as self-organizing systems. These systems may conversely be related to a wider notion of material activity that translates within the design field as a questioning of materials' traditionally supposed passivity in fabrication processes. 
behavior; and Manoeuvres, an interactive installation producing complex light patterns through the collective motion of physical units. ${ }^{17}$

\section{From Representation to Material Performance}

Since the advent of the modern architectural discipline in the Renaissance, most notably after Filippo Brunelleschi's innovations, ${ }^{18}$ the notion of design has been tied to the assumption of a fundamental divide, both temporal and social, between the world of the project and the world of matter [Boutinet 2002, p. 224]. At the same time, as it separates the designer from craft professions, and the architect from construction workers, design is also envisioned as the prime method through which the intellectual and physical worlds may be reunited [Picon 2004, p. 120]. This dialectic has traditionally defined design as an activity which, although separate and anterior to the concrete process of fabrication, claims a complete authority on the qualities of the latter's output.

Leon Battista Alberti's De re aedificatoria (On the Art of Building) [Alberti 1988], published in 1485, is the first architectural treatise to build upon this modern conception of design. Alberti's insistence on the role of design is expressed in his distinction between the concept of lineaments and the notion of structure, or construction: as noted by anthropologist Tim Ingold, “[w]hat Alberti [...] calls 'lineaments' (lineamenta) comprise a precise and complete specification of the form and appearance of the building, as conceived by the intellect, independently and in advance of the work of construction (structura)" [Ingold 2013, p. 50]. This distinction, central to Alberti's architectural theory, is laid out at the very beginning of the first book of On the Art of Building:

17 Both projects have been developed in the context of a PhD thesis undertaken at EnsadLab, the laboratory of the École nationale supérieure des Arts Décoratifs (EnsAD), from October 2013 to December 2017, under the supervision of Antoine Picon and Samuel Bianchini. This research was situated within the context of the Reflective Interaction group, led by Samuel Bianchini, as well the SACRe doctoral program of PSL University.

18 Filippo Brunelleschi, architect of the dome of the Santa Maria del Fiore cathedral in Florence, is known for his early experiments in linear perspective. The most famous of these experiments aimed at demonstrating the correctness of a perspective painting of Florence's Baptistery of San Giovanni, by means of a small hole drilled into the vanishing point of the painted panel and a mirror. For a global overview of Brunelleschi's life and inventions, see for instance [King 2000]. On Brunelleschi's relationship with perspective, see [Damisch 1995]. In respect to Brunelleschi's role in the history of the architectural discipline, scholar Jean-Pierre Boutinet considers him as the inventor of the architectural project in its modern sense. According to Boutinet, Brunelleschi's expertise in perspective drawing allowed him to propose for the first time "a methodology of the disegno, or in other words a methodology of the anticipation of the work to be carried out" [Boutinet 1993, p. 10 (translation I.L.)]. For more on the epistemological relationship between the architectural project and the broader concept of design, see: [Vial 2014]. 
[t]he whole matter of building is composed of lineaments and structure. All the intent and purpose of lineaments lies in finding the correct, infallible way of joining and fitting together those lines and angles which define and enclose the surfaces of the building. It is the function and duty of lineaments, then, to prescribe an appropriate place, exact numbers, a proper scale, and a graceful order for whole buildings and for each of their constituent parts, so that the whole form and appearance of the building may depend on the lineaments alone.

[Alberti 1988, p. 7]

Alberti's description of the lineaments' purpose clearly corresponds to what is referred to, in modern terms, as the design phase of a building: that is, a stage independent from and chronologically anterior to the building's construction that, however, intends to prescribe every detail of the final object. Noting that lineaments do not "have anything to do with material" [ibid.], Alberti continues: "[i]t is quite possible to project whole forms in the mind without any recourse to the material, by designating and determining a fixed orientation and conjunction for the various lines and angles. Since that is the case, let lineaments be the precise and correct outline, conceived in the mind, made up of lines and angles, and perfected in the learned intellect and imagination” [ibid.] (see Fig. 2).

This definition of the lineaments as a geometric specification ("made up of lines and angles" [ibid.]) of the building's final form, carried out in the intellectual space of the project and not within the material space of construction, has led architectural historian and theorist Mario Carpo to qualify Alberti's writings as a "notational method of design" [Carpo 2011, p. 77]. For Carpo, the concept of lineaments conveys an approach to architecture "predicated on the notational sameness between design and building, implying that drawings can, and must, be identically translated into three-dimensional objects" [ibid., p. 26]. The concept of notation, used by Carpo in reference to Nelson Goodman's book Languages of Art [Goodman 1968], expresses the new prescriptive and authorial power that Alberti's treatise ascribes to architectural drawings: with Alberti, drawings become plans in the modern sense, or, in Tim Ingold's terms, "full geometrical pre-specification[s] of the intended work" [Ingold 2013, p. 55].

This understanding of drawing as the privileged medium for communicating the forms conceived in the architect's mind relates directly to the Renaissance concept of the disegno, defined most notably by Giorgio Vasari, ${ }^{19}$ which refers both to the idea of design and its visual expression in the form of a drawing [Jack 1976, p. 4]: indeed, for Ingold, drawing in the Albertian theory of architecture can be understood as the "visual projection of an idea already fashioned in the intellect" [Ingold 2013, p. 55]. This understanding of the architect's role in relation to the production of the disegno sets architecture apart from craft professions, and their handling of the physical realities of the building site. Alberti's treatise thus stands at a "pivotal juncture" [ibid., p. 49]

19 The concept of disegno is central to Vasari's Lives of the Artists [Vasari 1998], first published in 1549-1550. 
in the history of the architectural discipline, and "looks forward to a time when the architect would prescribe only the formal outlines of the building, leaving its actual construction in the skilled and capable hands of workmen" [ibid.].

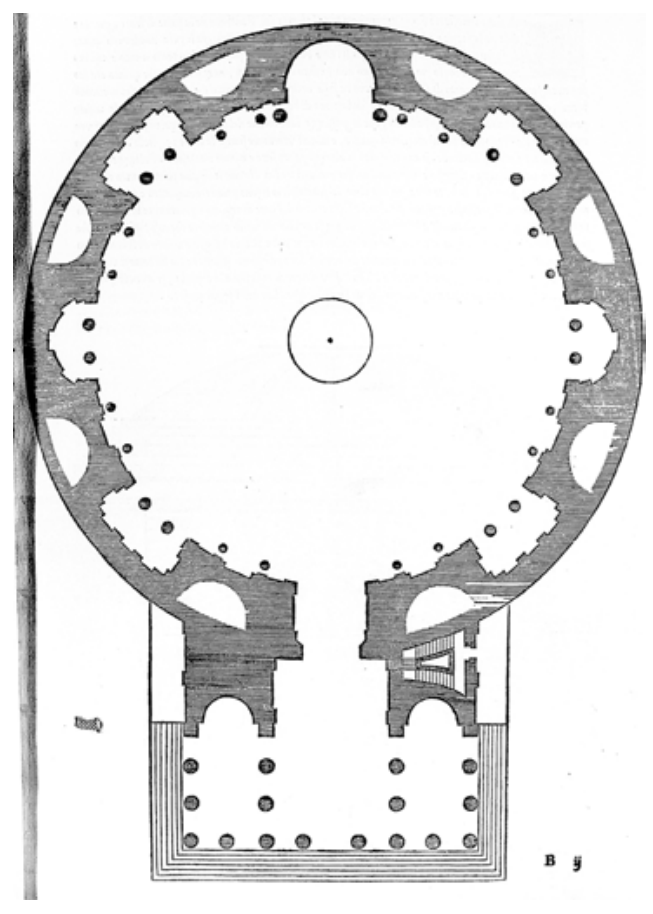

Fig. 2: Sebastiano Serlio [Serlio 1540, p. vii], plan view of the Pantheon. (c) Bibliothèque nationale de France (reproduced with authorization).

It should be noted, of course, that the professional distancing of architecture with building practice did not imply that construction issues would cease to matter to architects. Alberti's treatise itself includes extensive considerations about the material details of building, ${ }^{20}$ and historical examples abound of decisive architectural gestures owing their existence not to a planned decision but to contingencies happening during the physical construction process. One can mention here, for instance, the famous béton brut (raw concrete) finishes of Le Corbusier's Unité d'habitation de Marseille: confronted with material limitations, the architect made the choice of not attempting to uniformize the building's surfaces, which bore the marks and

20 Following the introduction of the concept of lineaments, the second book of On the Art of Building is thus devoted to the question of materials. 
imprecisions of the wood formworks employed during construction. Le Corbusier famously justified this move in aesthetic terms, explaining how one could truly envision concrete as a new type of raw material, worthy to be shown for its own qualities [Boesinger 1991, p. 190].

This impossibility of entirely reducing an architectural work to its plans and perspective renderings has in fact been understood as one of the idiosyncratic qualities of architecture's relationship with its "notational system" [Goodman 1968, p. 221]. Indeed, as noted sharply by architect and historian Robin Evans, the idea that architectural drawing could provide a "complete determination in advance" [Evans 1997, p. 156] of a building, while certainly untrue, has traditionally operated as a sort of defining and enabling fiction within architectural practice. According to Evans, the very possibility of architectural design may thus very well rest on a form of "suspension of critical disbelief” [ibid., p. 154] with respect to drawing's capacity to anticipate every aspect of the final object.

This generative relationship with the ambiguities and limits of design representation, however, appears at odds with the extensive precision and descriptive powers offered by today's digital design environments. Computer drawings, models, and renderings have offered an unprecedented capability to document and author every geometric, material and organizational aspect of a project, from design to fabrication. The growing popularity of design documentation environments, or Building Information Modelling software (BIM), which aims at organizing and quantifying every aspect of the production and life cycle of a building, emblematizes the industry's attempt to rationalize all aspects of material production thanks to digital representation technologies. $^{21}$ This agenda all but results from the expanding capacities of digital design and fabrication tools, whose early developments can be situated in the late 1940s.

Modern digital workflows, in the post-war period, developed out of a need to provide greater control over industrial processes, a goal which was approached by enforcing the use of reference geometric data (2D or 3D curves and surfaces) at all levels of the design to manufacturing pipeline. One can think, for instance, of Pierre Bézier's account of the development of UNISURF, the first interactive computeraided design and manufacturing (CAD/CAM) system, which he led at Renault factories in the mid-1960s. According to Bézier, UNISURF intended to ground the whole production process of a car body - from styling to manufacturing - on a single digital model, with the objective of ruling out the imprecise analog model making and

21 A BIM model is organized around a detailed 3D representation of a building, complete with all its technical systems and subcomponents. This 3D geometric model is supplemented with a range of data, such as manufacturers' specifications, material costs, environmental performance metrics, and parametric relationships between components. This integrated and information-rich 3D model constitutes a single authoritative reference on the basis of which standard documents (such as 2D construction plans) can be generated as needed. For more details on BIM, see for instance: [Kensek 2014]. 
measurement methods then commonplace in the industry [Bézier 1998]. Even though UNISURF's CAM capacities were mostly intended for prototyping and 3D visualization purposes, rather than the direct production of car body parts, the tool carried within it promise of enforcing a complete conformity between the fabricated cars and their original design.

Ultimately, progresses in the integration of CAD/CAM systems and industrial automation have led to a full realization of this promise in the concept of 'file to factory' processes, a notion that refers to the possibility of a seamless transition from design intent to automated manufacturing. Within this paradigm, any digital design asset is thought to contain, from the moment of its creation, all the information required to set in motion a full product production chain. This idea, although envisioned as a possibility as far back as the 1970 s, $^{22}$ still constitutes the guiding principles of today's perspectives for the future of manufacturing: the emerging production paradigm known as 'Industry 4.0,' whose conceptual basis lies in the realization of networks of cloudconnected, sensor-enabled manufacturing units - so-called 'cyber-physical' systems [Rajkumar et al. 2010] - aims at creating agile production pipelines able to respond, in near real-time, to any change in design specifications. ${ }^{23}$ The most recent advances in industrial manufacturing thus aspire, in a sense, to a quasi-ideal realization of the notational project underpinning modern design, by providing a framework for controlling all material aspects of production within the 'intellectual-digital' space of the project.

This agenda seems so deeply ingrained in CAD/CAM workflows, in fact, that the idea that digital prototyping alone could represent a revolution in design practices should be regarded with caution. For all the transformations brought about by the diffusion of a "making," or "digital DIY" [Anderson 2012, p. 21] culture in design, the greater access to fabrication capacities more often than not befits traditional design thinking, in which geometric form - encoded in a digital file - exerts full control over passive matter. One needs simply to think, for instance, about the very concept of online objects libraries, such as the platform Thingiverse, which provide a collection of user-contributed 'things,' ready to download and 3D print. Here, design is fully identified with the production of geometric form, and material qualities are relegated to a secondary role: the material used in the 3D printing process, as it seems, only matters so much as it proves compliant enough to reproduce the downloaded objects' geometric features.

\footnotetext{
22 See, for instance, the reflections presented by Alvin Toffler on the potentials of industrial automation in his 1970 bestseller Future Shock: [Toffler 1970, p. 236].

23 Several key European initiatives, such as the German government 'Industrie 4.0' program and the CREMA (cloud-based rapid elastic manufacturing) project, funded by Horizon 2020 Framework Programme, identify 'Industry 4.0' as a strategic priority for realizing the vision of an "European Industrial Renaissance” called for by the European Commission in 2014 (http://eur-lex.europa.eu/ legal-content/EN/TXT/?uri=CELEX:52014DC0014, accessed August 17, 2018).
} 
My goal, of course, is not to take position against the existence of such platforms which may be home to genuinely inventive projects - but rather to highlight the conservative vision of design they embed. Similarly, in the practice of many accomplished digital designers, materialization is still envisioned as a purely predictable and passive process, in contrast to the 'active' design phase, where the defining features of the object are created. Fabrication, it is often thought, is not able to alter or create form - not because of a technical limitation but rather as a consequence of a conceptual, almost moral impossibility: all material processes resulting in a deviation from the designer's original form are considered erroneous and are thus rejected.

The new design approach gathering strength in schools, laboratories, and practices, of which we have already seen a few examples in this chapter's introduction, is fundamentally more open to material processes yielding unpredicted formal output. Indeed, in projects such as Olivier van Herpt's works with clay, what is at stake is less the intentional production of 'errors' than the recognition of a fundamental form of material activity as a key morphogenetic driver within the design project. Beyond a mere visual interest in exploring 'discontinuous' or 'fractured' form, this emerging trend of design research thus hints at the fact that contemporary designers may be slowly coming to terms with a notational understanding of design that, with some notable exceptions, ${ }^{24}$ has prevailed since the Renaissance. As we shall see below, for designers operating within this framework, computation is increasingly used to design fabrication processes - which may trigger more or less predictable material responses - rather than the direct visual features of an object.

One key ingredient in this evolution is the fact that today's design workflows are increasingly attentive to the properties of materials and to the degrees of freedom offered by fabrication processes. The approach known as 'material computation,' investigated for instance by MIT researcher Neri Oxman [Oxman 2010], or in much of the research carried out by Achim Menges and his partners at Stuttgart's ICD, has gathered strength since 2010 around the idea that " $[\mathrm{m}]$ aterial properties, characteristics and behaviours can now be employed as active design generators" [Menges 2012, p. 16]. This approach has resulted in object or building-scale prototypes exploiting active material behavior, such as the hygroscopic bending of wood veneer panels in Achim Menges' and Steffen Reichert's HygroScope project [Menges

24 One can think here of the form finding experiments led by the German architect Frei Otto, already mentioned above. These experiments were based on dynamic physical models (such as soap films and wool threads) subjected to environmental forces. The 'equilibrium' configurations reached by these models would provide formal solutions to design problems. For more details about Frei Otto's architectural work, see: [Glaeser 1972]. On the generative use of physical models within architectural design processes, one should also mention the use of hanging chain models by Antoni Gaudí to determine the catenary curves used in vaulted ceilings. On this topic, see: [Huerta 2006]. 
and Reichert 2015], part of the Centre Pompidou permanent collection. Yet, with the exception of a few of such examples, material computation workflows more often materialize as physics-based simulations, which are incorporated into design programs to capture some aspects of 'real-world' dynamics. In this context, the design process' prime objective remains to provide a complete geometric description (in the form of a 3D model) of the objects to be manufactured. While the use of physicsbased simulations can certainly produce geometries more akin to comply with the materials' physical properties, the relationship between form and material still follows here a top-down dynamic. Somewhat counter-intuitively, given the name 'material computation,' form is not 'computed' by the actual performances of the material itself but by a geometric computer model representing the properties of this material. ${ }^{25}$

A more relevant notion to the transformation currently observed in design research may be the idea of "design hacking" [Witt 2011], which envisions the development of bespoke fabrication processes as a key part of the design project. Benefiting from the development of tools such as the electronics prototyping platform Arduino, ${ }^{26}$ a growing number of designers are today involved in the building and scripting of their own machining logics, often eschewing traditional assumptions in respect to how a CAD/CAM pipeline should operate. As an example, several researchers have proposed to generate machine toolpaths directly from the design phase, whereas most off-theshelf CAM software computes toolpaths after the design process per se, once a full geometric model of the target object can be provided. In Manuel Jiménez Garcia's and Gilles Retsin's work with the Bartlett's Design Computation Lab, continuity-based modeling is, for instance, replaced by a voxel-based approach [Garcia and Retsin 2015], in which machine toolpaths are directly generated according to local rules. The full fabrication toolpath, allowing for the manufacturing of the object by robotic polymer extrusion, is then built up from the aggregation of these unit trajectories: geometric data emerges here from fabrication logics, and not the reverse.

By vowing to engage with the design of fabrication processes, rather than the design of full geometric descriptions of the objects to be fabricated, such methods appear ideally suited to the creative and playful exploration of material behavior, beyond the limitations of digital description and simulation. Through 'design hacking' and related approaches, digital design thus appears on the verge of operating a 'performative turn,' in which the formative powers of active material behavior are

25 Notable exceptions to this statement include, as discussed above, projects such as Menges' and Reichert's HygroScope, which are able to dynamically 'compute' their shape through the mobilization of active material properties (such as hygroscopic wood bending). In this case, the shape configuration of the bending wood panels at any given time is not dictated by the 3D model defined in the project's design stage but results from an interaction between wood's physical properties and its environment.

26 https://www.arduino.cc/ (accessed November 4, 2019). 
given full recognition at all levels of the design project. It is in this challenging of design's comprehension as a notational, geometry-led practice that one may find digital design's most important contribution to the field of active matter - a field in which the very notion of design, in its most general sense, is increasingly understood as a fundamental and interdisciplinary concept [Schäffner 2010].

The prime issue, for today's digital designers, thus lies in the preparation of a form of openness to material behavior in the design process itself, in a context where conventional tools and CAD/CAM workflows enforce a linear, geometry-oriented approach to object production. The project Unspecified Clay, discussed next, aims at addressing some aspects of this question in a framework of clay-based additive manufacturing.

\section{Retroactive Production: Unspecified Clay}

\subsection{Context}

Unspecified Clay is a research project initiated in 2016 in collaboration with the Italian group Co-de-iT, a research and education-focused network investigating the impact of computational techniques within architecture, engineering, design, and craft. Developed primarily with Andrea Graziano, Marco Palma, Bruno Demasi, and Alessio Erioli, the project was carried out in the joint context of Co-de-iT's inFORMed Matter research project, and of the Responsive Matter program, led by the Reflective Interaction group of EnsadLab in Paris. Unspecified Clay was developed as an experimental production system within the framework of these two research initiatives, both undertaking investigations on the topic of active matter from an arts and design-oriented perspective.

As noted in the introduction to this chapter, Co-de-iT had previously led experiments involving the production of emergent material structures in a clay-based additive manufacturing context, through the mobilization of buckling and deformation effects. While this research made an extensive investigation into emergent material behavior, the latitude of the material effects it focused on was in fact entirely set up in the design phase, as no feedback from the material to the digital domain was implemented. When I approached Co-de-iT in 2016 to propose the initial concept of the Unspecified Clay project, we thus agreed on aiming to challenge the linearity of the design to manufacturing pipeline that still characterized these previous experiments, which we identified as the main bottleneck toward implementing a greater openness to material behavior in design workflows.

Accordingly, Unspecified Clay was posited as a retroactive production setup, in which feedback processes would allow a robotic manufacturing unit to build artefacts through repeated cycles of deposition, scanning, and computation. This setup was primarily designed with the intent of exploring the generative potentialities of a reciprocal process of interaction between clay's self-organizing properties and 
computational logics. Instead of aiming at the materialization of pre-defined digital models, our motive was rather to develop a production system able to discover and foster aesthetic and structural opportunities, emerging from an 'autonomous expression' of material behavior. By this term, we want to convey the idea that the material's main physical properties (such as its density and plasticity) would become generators of form, rather than constraints in a manufacturing process whose output would be determined in advance. In other words, we aimed to let the material organize itself according to its own laws, rather than constraining it to achieve an a priori defined geometric objective (as would be the case, for instance, in a clay molding process). The prime content of the research thus focused on designing a computational system able to negotiate and collaborate with this autonomous expression of clay behavior, with the objective of developing emergent material structures. Our approach to this question centered on implementing sensing and machine vision processes that would allow our digital system to be informed at each fabrication step of the material's configuration. In the remainder of this section, we describe our approach to implementing such a retroactive production process and discuss our empirical investigations and results.

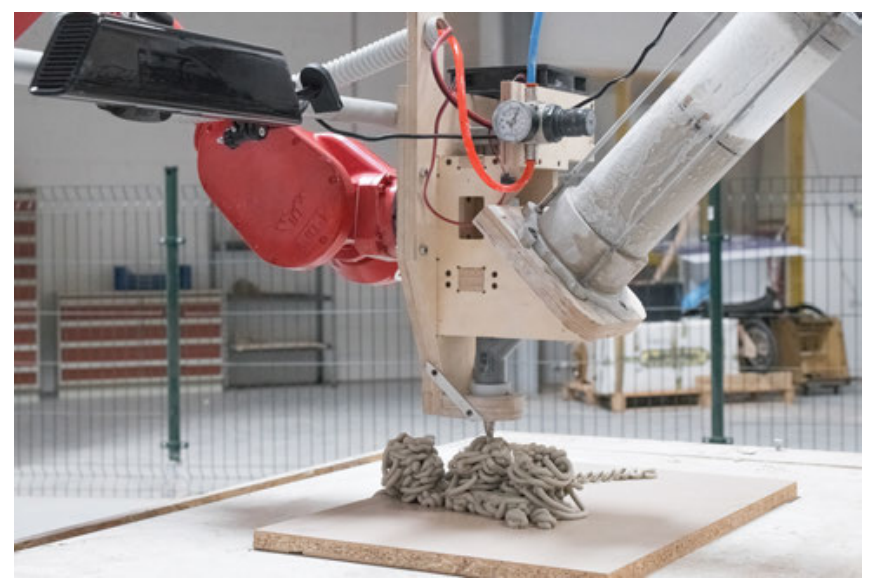

Fig. 3: Unspecified Clay’s experimental setup. (c) Ianis Lallemand.

\subsection{Experimental Setup}

This initial concept led us to develop the setup shown in Fig. 3. A custom clay extruder, developed by Co-de-iT, is mounted on a six-axis industrial robotic arm (COMAU NS12), which also has a Microsoft Kinect sensor, an infrared-based technology able to compute depth maps of close-range scenes [Zhang 2012]. The robot control program, as well as the system's other computational procedures, including data processing and sensor calibration, are implemented within a single application (Fig. 5), developed with the programming environment processing. Following the idea of a closed feedback loop 

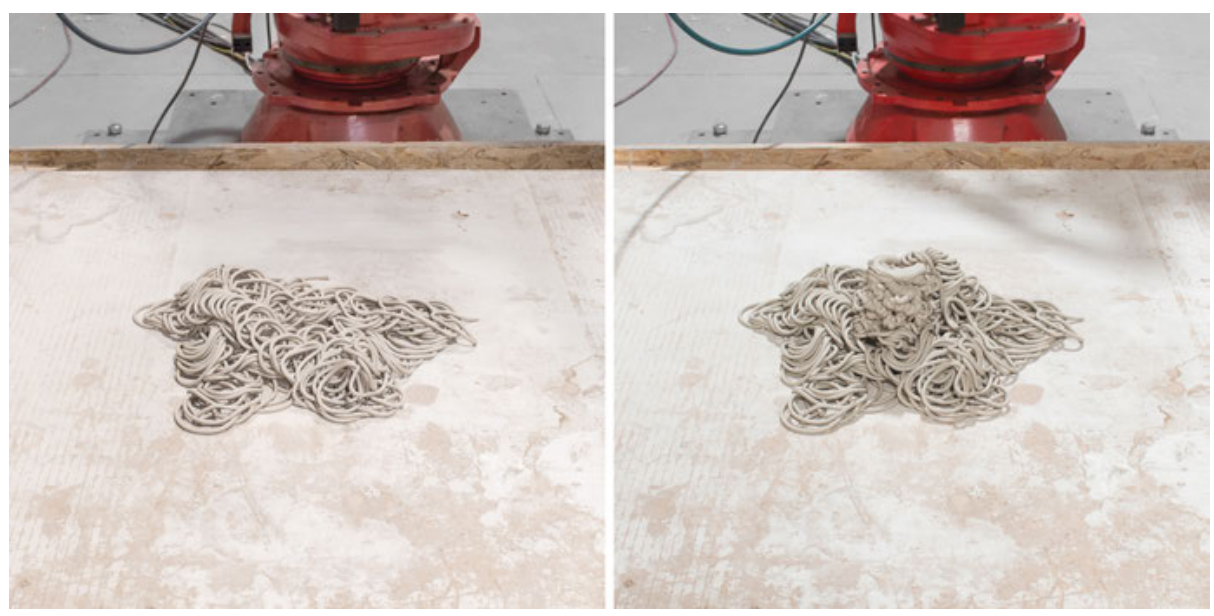

Fig. 4: Two successive steps in Unspecified Clay’s fabrication process. () lanis Lallemand.

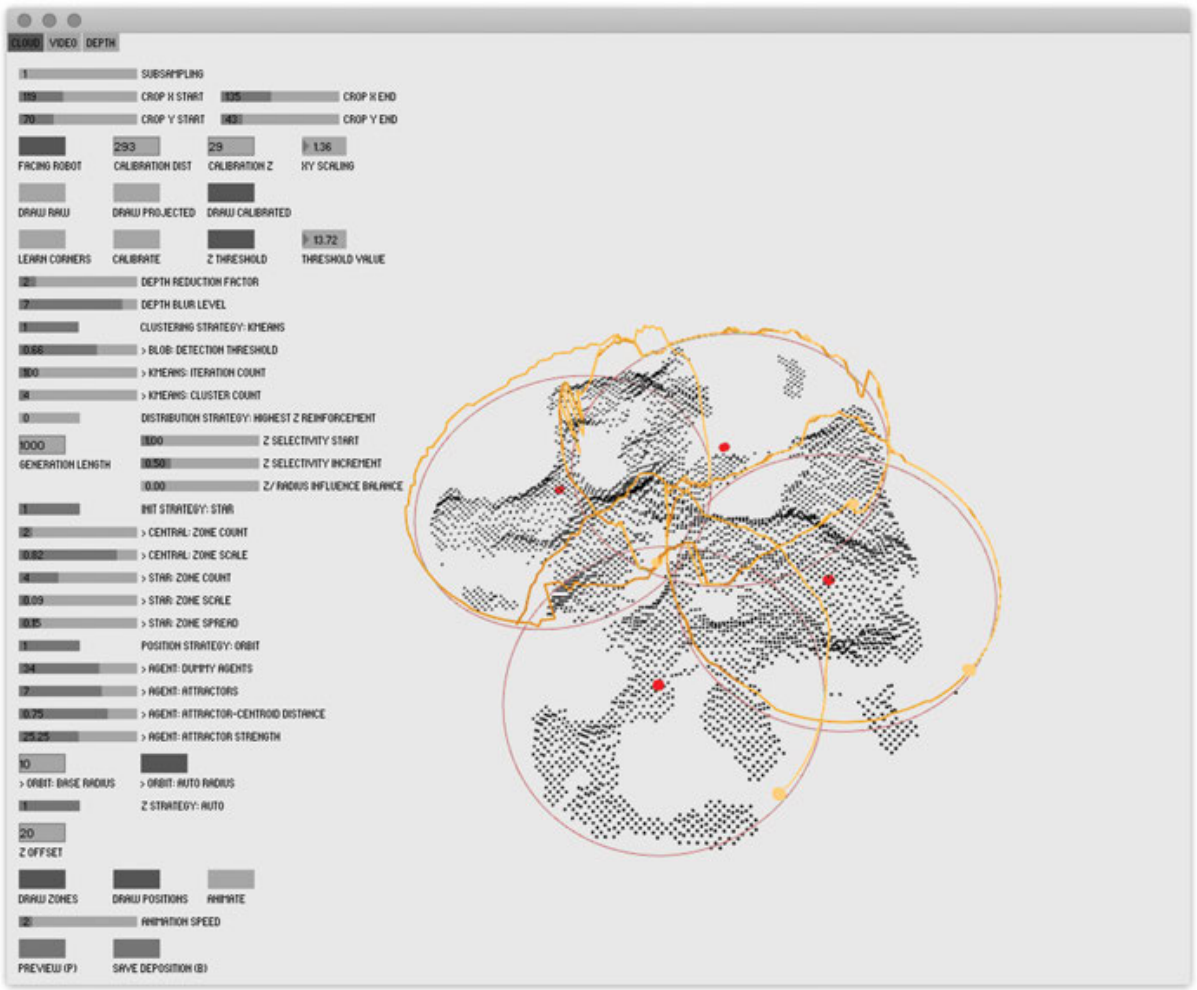

Fig. 5: Processing application developed for the Unspecified Clay project. ( Ianis Lallemand. 


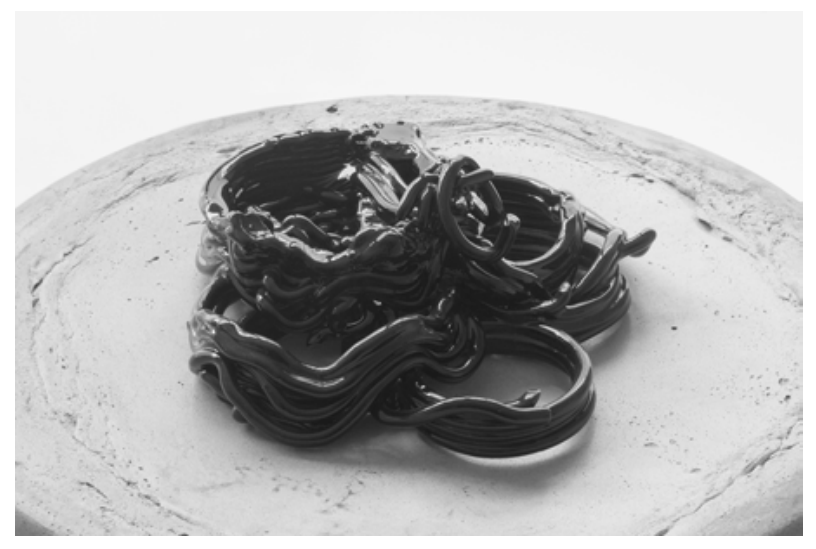

Fig. 6: A finished, glazed ceramics piece. (C) Ianis Lallemand.

between fabrication outcomes and generated robot toolpaths, each fabrication session is organized as follows:

1. Perform a first series of clay depositions at heuristically selected locations of the working area;

2. Capture the obtained clay structures with the Kinect sensor and compute a 3D point cloud representation of the acquired depth map;

3. Generate robot trajectories based on point cloud data and perform a new series of clay depositions;

4. Repeat steps 2 and 3.

Figure 4 shows two successive steps of the fabrication process, while Fig. 6 shows an example of a finished ceramics piece produced in our experiments, which has been fired in a kiln and coated with a black glaze. With the exception of the first iteration of the fabrication process (step 1 in the list above), Unspecified Clay's output can be described as essentially emergent: no global 3D model specifying the shape of the final object is ever handled by the system, and all form-generating processes - whether computational or material - are realized in 'real-time' within the fabrication phase. This latter characteristic inscribes Unspecified Clay within a background of related design research, which we will briefly discuss below.

\subsection{Related Work}

Within the set of design research work eschewing the production of traditional 3D models in favor of a direct generation of machine control codes, a small number of approaches have explored the possibility of performing an online adaptation of robotic toolpaths in response to material behavior. As with our approach, most of these projects have resorted to sensing capabilities and feedback mechanisms, 
either to channel emergent material behavior into the realization of a given shape target, or to develop it for generative or aesthetic purposes.

The project Remote Material Deposition [Dörfler et al. 2014], developed in the context of the research laboratory of architects Gramazio \& Kohler, at the ETH in Zurich falls within the first of these two categories. The project aims at tackling the scale issue intrinsic to robotic fabrication processes, which are usually limited by the work envelope of robots and therefore ill-suited to full-scale architectural applications. In this context, Gramazio \& Kohler's team developed a robotic fabrication method based on the throwing of cylindrical clay loam units, with the purpose of building protoarchitectural structures (walls) over a distance. To handle the uncertainty introduced by the units' deformation on landing, the method makes use of machine vision to adjust the throwing trajectories to previously formed aggregations, thus allowing for a channeling of material behavior toward the realization of a selected floor plan.

Other research ${ }^{27}$ investigates the use of feedback mechanisms from a more generative viewpoint, in the respective contexts of plastics, wax, and polyurethane foambased manufacturing processes. In these works, feedback does not aim at comparing the fabrication's current state to a pre-defined reference but rather at enabling the system to 'go on' from whatever emergent state it has reached previously.

While Unspecified Clay appears closer to these latter examples in terms of intent and conceptual background, its adoption of clay as a working material forces it to face a different set of morphogenetic issues. In contrast to rapid-hardening materials such as polyurethane foam or wax, clay will typically maintain a plastic behavior throughout the whole duration of manufacturing. This exposes our setup to the effect of indeterminate material deformations, both during and after printing (as the addition of new clay creates extra compressive stress on existing structures). As we mentioned earlier, Gramazio \& Kohler's Remote Material Deposition research also featured similar deformation events; yet, the staging of these in a generative, openended workflow constitutes, to our knowledge, a novel research issue, which Unspecified Clay is thus first to explore.

\subsection{Hypothesis and Methods}

Unspecified Clay makes the hypothesis that the maintained plasticity of deposited clay can be computationally channeled into the production of materially differentiated artefacts, exhibiting variable properties of density, texture, and articulation. This hypothesis was experimentally tested through the implementation of two main sets of procedures.

27 See, for instance, Matias del Campo et al.'s Autonomous Tectonics [Del Campo et al. 2013], Ryan Luke Johns' Augmented Materiality [Johns 2014] and Roland Snook and Gwyllim Jahn's Stigmergic Accretion [Snooks and Jahn 2016]. 


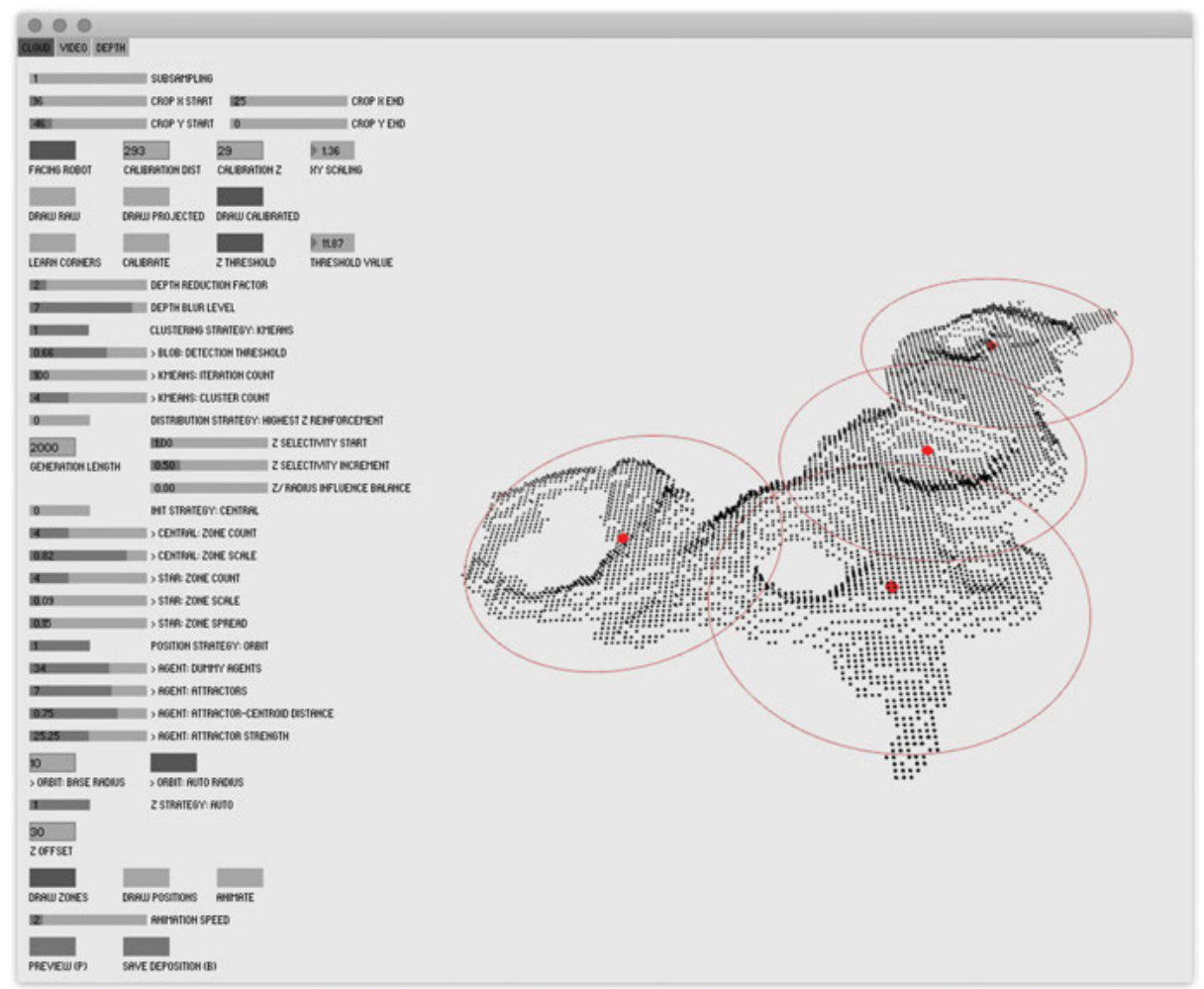

Fig. 7: Example of candidate deposition areas detected by the Unspecified Clay software. (C) Ianis Lallemand.

Sensing - To generate new deposition trajectories from the scanning of previously deposited structures, the system first computes a set of candidate deposition areas from the 3D point cloud morphology by using a K-means algorithm (Fig. 7). In each detected cluster, an agent-based simulation is instantiated and configured given the cluster's properties (area and centroid height). The generated agent positions are then automatically translated into robot control code, using so-called linear motion instructions (i.e., while keeping the extruder's vertical orientation constant). The implemented algorithm allows for the generation of a wide range of trajectories, from dense and intricate paths derived from Craig W. Reynolds' swarming simulation model [Reynolds 1987] (Fig. 8), to orbit-like revolutions around cluster centers. ${ }^{28}$

28 The swarming simulation model is here taken as a heuristic approach to the generation of deposition toolpaths. More specifically, the characteristics of the model enable the generation of spatial curves with a controlled degree of redundancy and self-overlay - managed through the tuning of the simulation settings - while adopting ever-changing morphologies. These two characteristics are suitable in the context of the discussed experiment, as they allow for a building up of clay in 


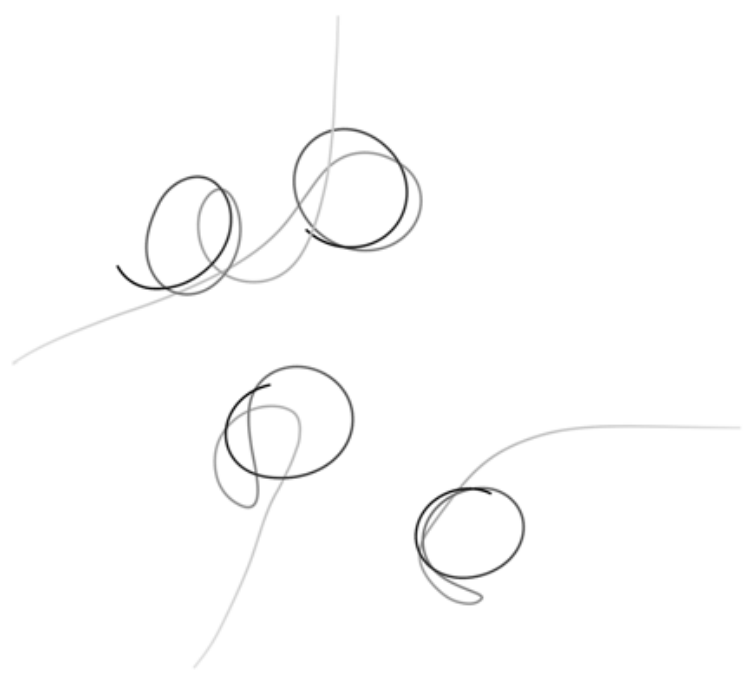

Fig. 8: Example of trajectories produced by Unspecified Clay's toolpath generation procedure. A swarming algorithm is here instantiated within four detected clusters. (c) Ianis Lallemand.

Deposition focusing - We chose to progressively focus the toolpath generation algorithm on the most salient morphological features of the print, as a means to induce material differentiation through a gradual, deformation-based shaping of these features. After the fabrication process' first iteration, in which loosely articulated formations are obtained from simple geometric forms (such as circles arranged in a star-like configuration), the system thus proceeds to identify, select, and reinforce the highest material clusters. The algorithm implementing this behavior acts on two physical parameters: the allocation of extruded material between detected clusters, and the vertical distance between the extruder's nozzle and the extrusion's target surface (the main parameter controlling material organization). A reward mechanism progressively drives the material allocation procedure toward favoring higher clusters, while the extruder's vertical offset relative to the deposition surface is slightly decreased after each iteration. The result is an increasingly selective deposition behavior obtained by: (i) allocating more material to the 'fittest' emergent structures, thus increasing the effects of clay deformation, and (ii) achieving greater organizational density in these areas through the progressive focusing of deposited mass, induced by the reduction of the extruder's vertical offset.

This algorithm is implemented using a simple reward mechanism based on a power function of the form $r=z^{\alpha}$ where $r$ is the reward allocated to a given deposition zone, $0<z \leq 1$ is the normalized height of the zone's centroid, and $\alpha \geq 1$ is the 


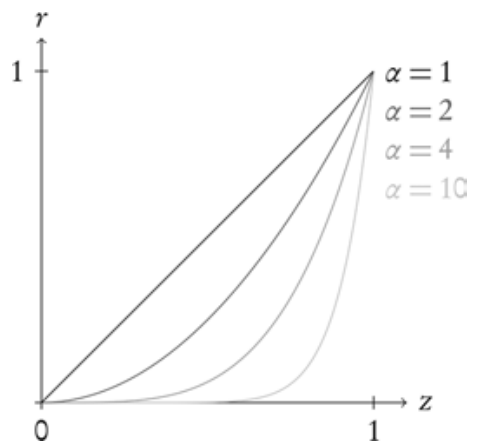

Fig. 9: Evolution of the power function used in Unspecified Clay's reward procedure under changes of the $\alpha$ parameter. () Ianis Lallemand.

reward mechanism's selectivity parameter. After computing $r$ for each deposition zone, the system divides the obtained values by the sum of all attributed rewards, yielding the proportion of the total number of deposition points to allocate to each centroid. Initially set at $1, \alpha$ is incremented by a fixed value after each iteration - an operation which, by increasing the convexity of the reward function (Fig. 9), provides a simple way to make the reward mechanism increasingly selective toward higher clusters. After enough iterations, this process would ultimately result in a single cluster, winner-takes-all focusing strategy.

In addition, the extrusion's vertical offset is decreased at a constant rate after each iteration, typically shifting from $50 \mathrm{~mm}$ to $10-20 \mathrm{~mm}$. When computing new deposition trajectories, this offset is locally added to the height information provided by the point cloud representation of previously deposited structures. This allows agents from the trajectory generation algorithm to maintain a constant vertical offset relative to prior topography, reducing the risk of collisions between the robot and already present material.

\subsection{Results and Discussion}

Three material samples resulting from different fabrication sessions are presented in Figs. 10-12. They have been obtained with different agent simulation parameters, while maintaining the same settings otherwise. This process allowed us to evaluate the adaption of the implemented deposition focusing procedure to different material morphologies, induced by several modes of toolpath generation.

Overall, the performed experiments tend to validate our initial hypothesis of being able to channel, through computational means, emergent material behavior into differentiated structures. In particular, the samples highlight our approach's capacity to achieve an increase of organization along the extrusion's vertical axis. In each of the samples shown in Figs. 10 and 11, the initial, loosely structured mass has progressively 

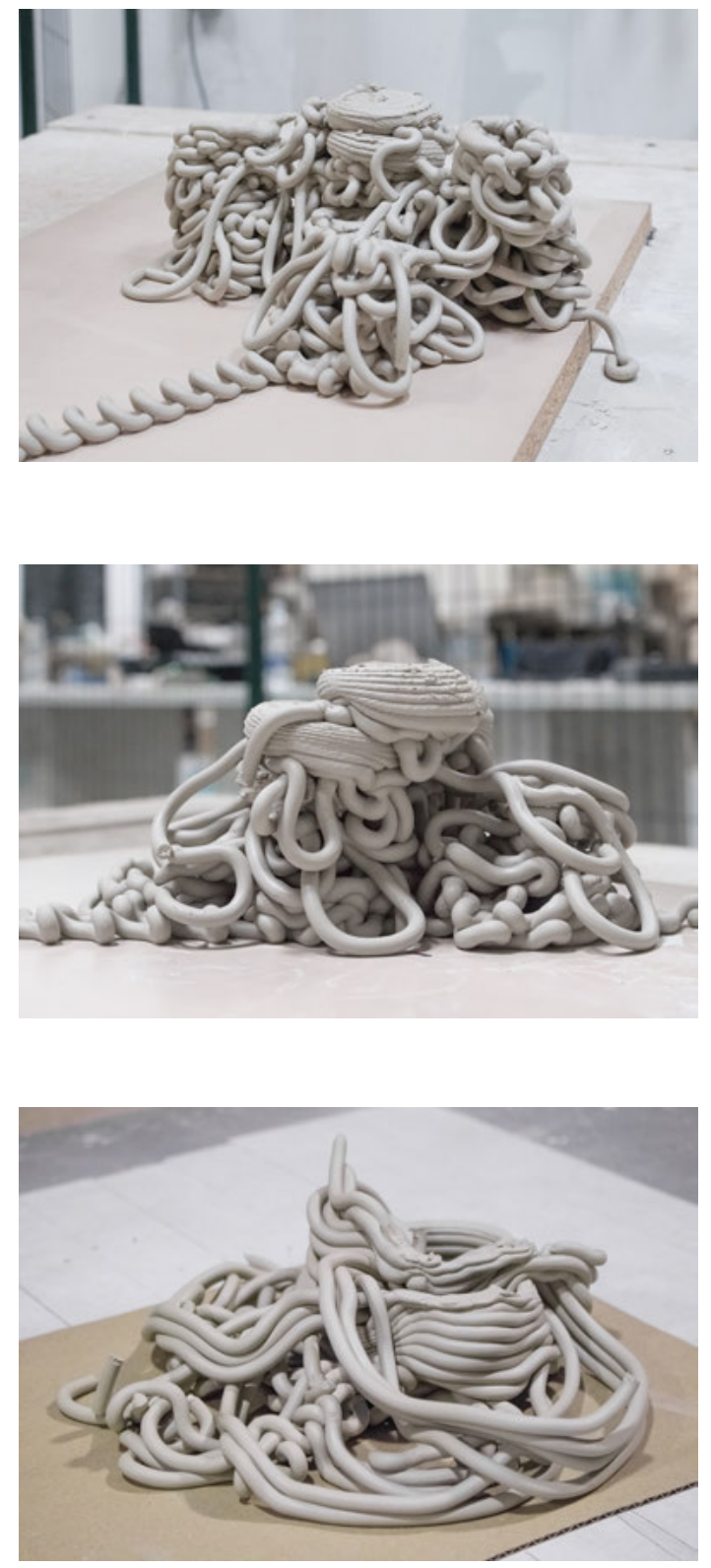

Fig. 10: Experimental sample produced as part of the Unspecified Clay project. (c) Ianis Lallemand.

Fig. 11: Experimental sample produced as part of the Unspecified Clay project. (c) Ianis Lallemand.

Fig. 12: Experimental sample produced as part of the Unspecified Clay project. (C) Ianis Lallemand.

been re-shaped into a few higher density clusters, through the addition of increasingly targeted depositions. In the highest clusters, further differentiation has been achieved as the algorithm drove the extruder to operate in direct contact with the clay, resulting in characteristic flat-topped structures. Figure 12 exhibits a more layered morphology, 
induced by the use of orbit-like agent trajectories. This example suggests that the fabrication can be intentionally steered toward different structural typologies by means of high-level parameters, while achieving local organizational details through the autonomous interaction of algorithmic and material behavior.

In its current form, the system provides a proof of concept of a retroactive, claybased production system, intended primarily for generative explorations. The project's technological developments, however, are susceptible to applications in the broader context of sensor-enabled robotics. Retroactive reward strategies, as implemented in Unspecified Clay, allow fabrication algorithm designers to use actual material behavior as a validator of previous robotic actions, making it possible to work with a broader class of material processes, regardless of the latter's propensity to be digitally simulated.

As a conclusive note, here, we should acknowledge the two main limitations of the project in its current state, which will be the subject of future work. First, the implemented clustering strategy (K-means algorithm) requires manually setting the numbers of clusters to detect. While the gradual increase in convexity of the reward function $r=z^{\alpha}$ leads to the automatic pruning of non-relevant clusters over time, our system may still fall prey to an overestimation of the cluster count in the first iterations of the fabrication process, where the reward function's selectivity is virtually nonexistent. Tackling this issue would require developing a new clustering strategy involving a form of morphological analysis of the point cloud data, so as to better adapt the search procedure to the real features of the deposited clay.

A second limitation of our current approach rests in its handling of possible collisions between the extruder and previously printed structures. While each generated toolpath makes use of the local topographic information provided by the point cloud, no check is currently performed to ensure that the extruder's body does not collide with structures adjacent to the toolpath. Embedding the effector's geometry into the trajectory generation routine would provide an immediate solution to this issue, yet the problem might be better approached by rethinking how the robot moves in space, in order to allow the use of a greater range of motion commands (and not simply linear ones). This approach would require implementing an inverse kinematics solver into the application, which would signal a deeper integration of manufacturing logics into the system's design.

\section{Manoeuvres}

\subsection{Context}

As stated before, one of the most salient manifestations of the increasing relevance of 'active matter' in design lies in the field's increased proximity with other research 
areas, such as physics and materials science. The Manoeuvres project, discussed in this section, provides a concrete example of how this conceptual proximity might evolve into design research collaborations.

Initiated amid the growing involvement of EnsadLab in the Arts \& Sciences movement, ${ }^{29}$ and benefiting from this laboratory's long tradition of exchanges with its neighboring scientific institutions, Manoeuvres has been developed in collaboration with physicist Olivier Dauchot. ${ }^{30}$ The project finds its origins in one of the team's experiments, initiated in 2003 to explore the collective motion of self-propelled disks, or 'walking grains.' Situated within the field of active matter, this research aimed at creating a model experiment demonstrating the same type of behavior as Tamás Vicsek et al.'s influential theoretical model, published in $1995 .^{31}$

With the aim of achieving precise experimental control, EC2M's setup was designed to eliminate all forms of external influence, like biological or chemical factors, in the production of the grains' motion [Deseigne, Dauchot, and Chaté 2010, p. 1]. To this end, EC2M thus elected to build a fully designed and artificial system, which they describe as the first "well controlled experiment" [ibid.] able to create large scale collective motion - or a "fluctuating, collectively moving ordered phase of the type frequently observed in simple numerical models" [ibid.]. To achieve this result, EC2M used purely mechanical means to set up each grain into directed motion, in an attempt to produce the local alignment behavior central to Vicsek et al.'s model. The experiment employs specially designed grains, equipped with a mechanically 'active' structure, and a homogeneous source of energy in the form of a vibrating plate on which the grains stand. The grains' design (Fig. 13) consists in a $4 \mathrm{~mm}$ diameter, micro-machined copper-beryllium disk, bearing two 'legs' on its bottom side: a copper-beryllium tip, machined from the same stock as the disk, and a rubber skate glued to the disk's surface. This structure, composed of two standing points having different mechanical

29 EnsadLab's mother institution, EnsAD, is a founding member of the first Arts \& Sciences chair in Europe, along with the École polytechnique and the Daniel \& Nina Carasso foundation: http:// chaire-arts-sciences.org/ (accessed August 24, 2018). The SACRe doctoral program, in the context of which Manoeuvres was developed, is also a key driver of Arts \& Sciences projects within EnsadLab.

30 Director of the Collective Effects and Soft Matter team (EC2M) of the laboratory Gulliver UMR 7083 at the École supérieure de physique et de chimie industrielles de la ville de Paris (ESPCI).

31 Vicsek's model was introduced to study the behavior of nonequilibrium systems [Vicsek et al. 1995, p. 1226]. More specifically, in the original article in which it was first presented, the model was used to demonstrate the existence of a kinetic phase transition (characterized by the alignment of particle velocities) in "systems of particles with biologically motivated interaction" [ibid.]. Although theoretical and based on computer simulations, the article indeed compared its results to the collective behavior of biological systems such as "schools of fish, herds of quadrupeds, or flocks of flying birds" [ibid.]. From a practical viewpoint, the model consists in a simple velocity update rule: at each time step of the simulation, the new direction of motion of each particle is set to "the average direction of motion of the particles in its neighborhood of radius $r$ with some random perturbation added" [ibid.]. 
response under vibration, creates a polar asymmetry which allows the grain to achieve directed motion, in the rubber skate to tip direction. The type of ordered formations produced by the experiment is visible in Fig. 14, showing a zenithal view of the vibrating plate (cropped to its circular boundary).

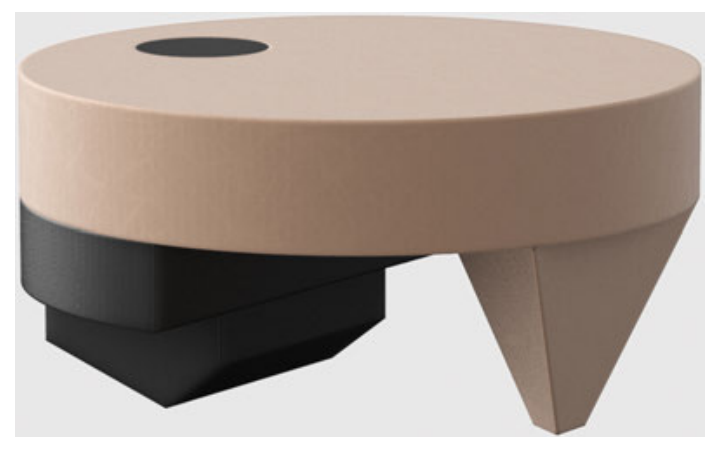

Fig. 13: View of the grain design used in EC2M's original experiment. (c) lanis Lallemand.

From a designer's point of view, one of the most striking features of this experimental setup undoubtedly resides in its 'analog' nature: the system appears completely devoid of digital control, at the exception of the simple function generator plugged into the vibrating plate. The local alignment behavior followed by the grains, and the resulting collective motion achieved by the group, both arise here, in fact, as purely emergent outcomes of physical collisions, whose dynamics are not controlled by any kind of programmed rule. This original approach, which struck us upon our first visit of the laboratory, appears to be in direct contrast to the direction most commonly assumed in the field of design research, where the topic of physical swarming systems has been subject to several investigations in recent years. Physical realizations of multi-agent simulations - which have been extensively used in the digital design community over the last two decades ${ }^{32}$ - have indeed, up to now, been primarily investigated from a robotics-oriented viewpoint, in projects such as the drone-based flight-assembled architecture, realized by Gramazio \& Kohler's research lab in collaboration with Raffaello D'Andrea's team at the ETH Institute for dynamic system and control [Augugliaro et al. 2014]. In such projects, the adopted approach - coincident

32 The use of such methods in digital design was certainly favored by the field's close relationship with the animation community (to which Craig W. Reynolds belonged) in the mid-1990s, as famously illustrated by Greg Lynn's use of animation software in his early work (see for instance [Lynn 1999]). Current uses of multi-agent algorithms include the generation of complex geometries [Snooks 2012] or the tackling of optimization tasks such as, for instance, the determination of an adequate tessellation of an architectural shell given aesthetic as well as digital manufacturing constraints [Schwinn and Menges 2015]. 


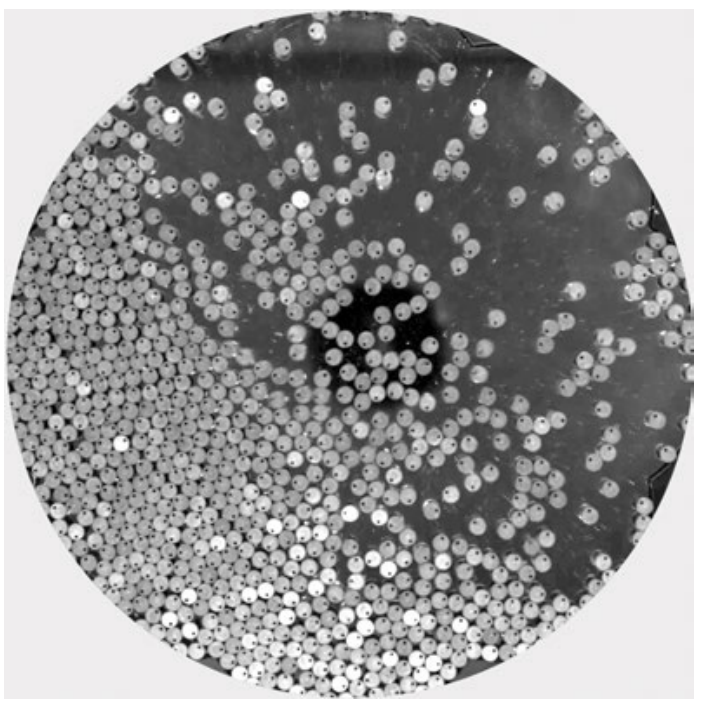

Fig. 14: The 'walking grains' original experiment (view from above). (C) Olivier Dauchot, Gulliver laboratory UMR CNRS 7083, ESPCI Paris (reproduced with authorization).

with current robotic research in collective behavior ${ }^{33}$ - focuses on the programming of rules at the unit level. Alignment behavior is then produced through a combination of digital sensing and motor actuation, which ensures the proper response of every unit to these built-in rules.

While this research direction offers the advantage of lending itself to the realization of many types of applications, including large-scale construction tasks, its rulebased approach requires setting up a technological apparatus that might not fit all types of design projects. In particular, the field of interactive or 'practicable' installations - image, sound, or shape-production devices calling for a physical engagement of their viewers ${ }^{34}$ - has recently witnessed a growing interest for the use of passive $^{35}$ actuators based on responsive materials, which offers a lower level of perceived complexity than digital systems. The Lotus Dome installation, by the Dutch artist Daan Roosegaarde, takes for instance the form of a hemispheric assemblage of heat-responsive 'smart foils,' at the interior of which rests a motorized stage light: when a person approaches the dome, the light rotates and illuminates the viewer, heating and 'opening' the smart foils on the beam's path (Fig. 15). Besides its evident poetic qualities, this project also offers distinct advantages in terms of maintenance

33 See, for instance, the Kilobot project, led by Harvard University's Self-Organizing Systems Research Group: [Rubenstein et al. 2014].

34 For a more thorough definition of the notions of interactive and practicable artwork, as well as a discussion of their relevance from an art-historical perspective, see, in particular: [Bianchini and Verhagen 2016].

35 We use here the term 'passive' to describe an actuator not drawing energy from an electrical power supply. 
over motor-based installations: the foils, devoid of internal mechanics and not dependent on a digital controller, are much less likely to fail during the work's operation. Far from being trivial, this feature constitutes a crucial argument for the use of material-based actuation mechanisms in contemporary art and design contexts.

In light of these reflections, we envisioned EC2M's experiment as a unique opportunity to approach the design of an agent-based, interactive production system, allowing for the creation of form through physical - rather than simulated - collective behavior. This realization led us to the development of Manoeuvres, of which we will now present the main concept and design principles.

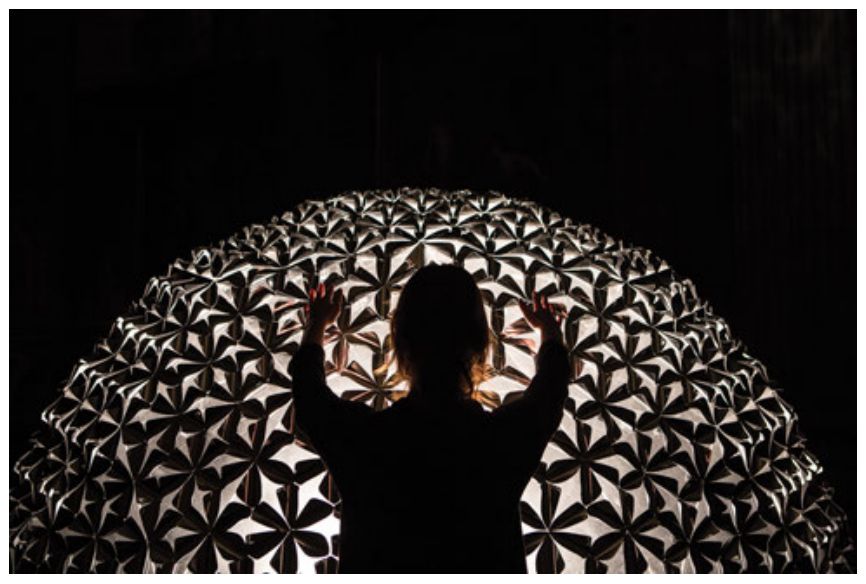

Fig. 15: View of the Lotus Dome installation by Dutch artist Daan Roosegaarde. (c) Roosegaarde Studio (reproduced with authorization).

\subsection{Concept}

The opportunity of designing an interactive system in dialog with EC2M's research was approached through the formulation of a light projection concept: we proposed to translate the collective motion of self-propelled units, or 'grains,' into a moving image, by equipping each unit with a rod-shaped structure, and casting the shadow of the latter on a surface. The projection was to be calibrated so that the shadows could reach about $1.8 \mathrm{~m}$ in height, creating a landscape of abstract yet human-scaled figures. Figure 16 shows a preparatory drawing of this concept, as well as a digital render of the expected light projection effect. By reference to EC2M's research, we envisioned to build a vibration-based system, at times robust and visually simple, with the objective of inviting the viewer to engage in a direct interaction with the system's behavior. Initially left open, the question of the viewer's mode of interaction became evident once the project had reached its first functional stages: thanks to the analog nature of the motion, and the natural 'grip' provided by the grains' rods, we realized that the viewer could easily manipulate the grains by hand, like pieces in a game of checkers - with the exception, of course, that the pieces would here move in an 
autonomous fashion. This 'analog' physical interaction ultimately suggests a blurring of boundaries between the viewer's and the grains' behaviors, an idea reflected in the production of a human-sized image out of the grains' shadows.
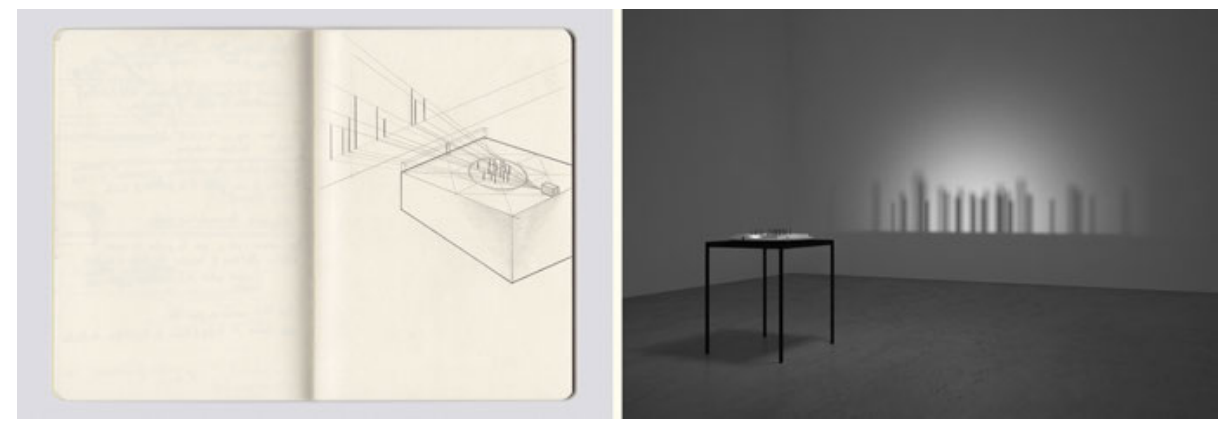

Fig. 16: Initial concept drawing and digital rendering of Manoeuvres. () Ianis Lallemand.

The ambition of inducing a form of proximity between the system and its viewers arose from the zoomorphic or even anthropomorphic associations that most observers would use when describing EC2M's original experiment, whether they were highly familiar with it - as in the case of the team's own personnel - or being confronted with it for the first time. Although being completely inert, and lacking any zoomorphic or anthropomorphic features on their own (due to their simple, disk-like shapes), the grains where indeed frequently compared to insects, animals, or even human beings, when commented on in the context of their collective behavior. While many of these comparisons would hold from a scientific viewpoint - in the same way as Vicsek et al.'s work can be said to model the principles behind some natural systems' behavior, such as bird flocking - we found most promising, from an artistic point of view, to approach the grains' motion as the model behavior of a human crowd. In this context, we imagined Manoeuvres as staging an interplay between two projection processes: the mental projection of a human behavior into the motion of inert, non-figurative objects, and the light projection of these objects' contours into a symbolic, shadowformed 'crowd.'

\subsection{Design}

Manoeuvres' design was naturally inspired by EC2M's original experiment, as required for the production of the same type of collective behavior which it originally displayed. However, beyond general principles (such as the use of an 'active' material structure in order to drive the grain's motion), EC2M's experiment could not be reproduced 'as is.' Given the small original grain diameter $(4 \mathrm{~mm})$, larger grains were in fact needed to carry shadow-casting rods, of a sufficient section, in a stable way; this 
in turn implied designing a larger vibration system than the one originally used by EC2M. Due to the complexity of the coupling between the grains and the plate, this sizing up of the system's core elements meant that the existing design for the grains legs could not simply be reused in a scaled form, and that a new design, fitting our system's properties, had to be developed through experimental testing. Although our system could have, in theory, made use of the same vibration production mechanism as EC2M's experiment (an industrial, electromagnetic servo-controlled shaker), convenience and cost considerations drove us to develop an alternative solution. Our discussions with Olivier Dauchot, revealing a mutual interest for approaching the problem through a 'hacking' mindset, led us to adopt inexpensive and quickly iterable manufacturing processes, like 3D printing, and off-the-shelf components, such as loudspeakers or surface transducers, to develop a more economical, lighter vibration system. Although not offering the level of control ex-

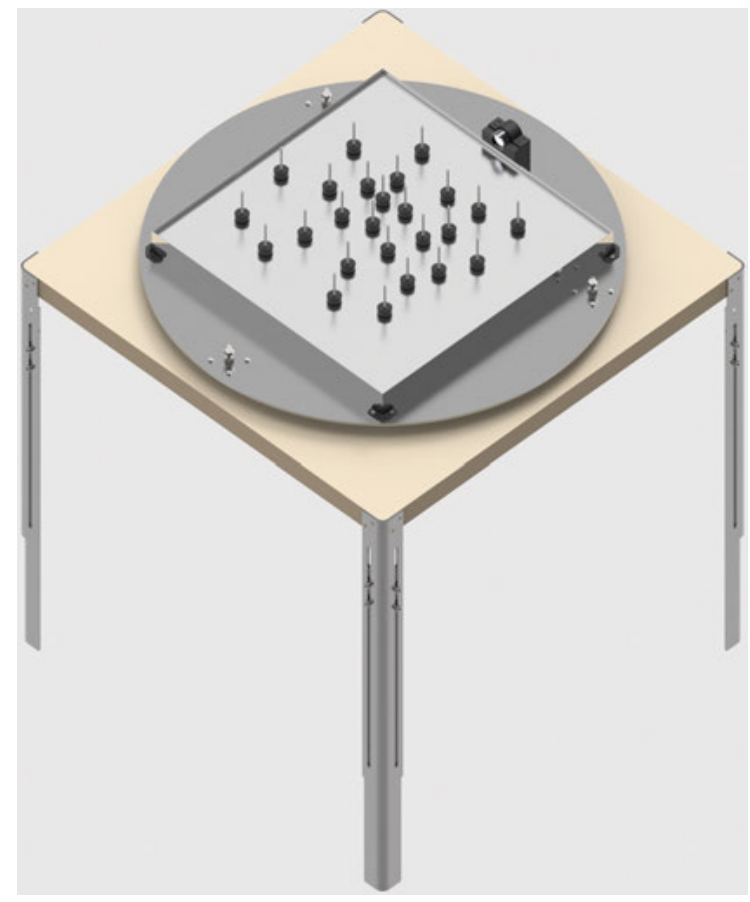

Fig. 17: Rendering of Manoeuvres' final setup. (C) Ianis Lallemand.

pected from a scientific apparatus, this approach constituted a viable solution in the design-oriented context of Manoeuvres.

The resulting setup, shown in Fig. 17, is composed of five main components: a table, a disk-shaped support frame, a square-shaped vibration unit, an LED lamp, and a set of walking grains. Figure 18 shows a detailed view of the frame's and 


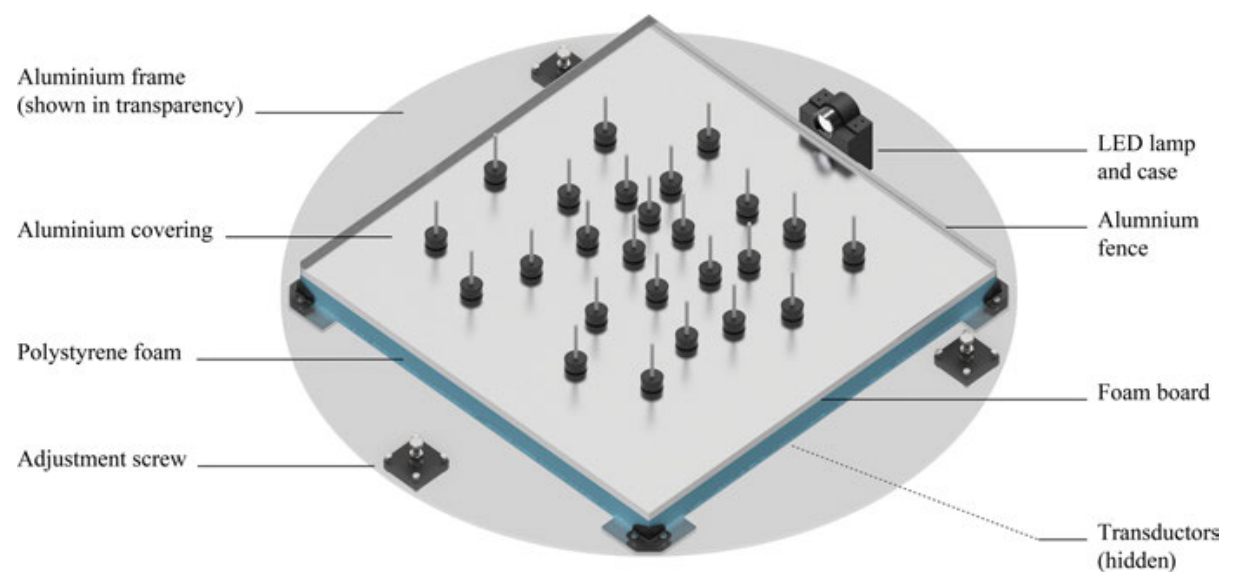

Fig. 18: Detail of Manoeuvres' vibration system. The vibration system is pictured in a cutaway view to reveal its internal structure. (C) lanis Lallemand.

vibration system's components. The frame, waterjet-cut from a $5 \mathrm{~mm}$ thick aluminum sheet, has a $750 \mathrm{~mm}$ diameter circular profile. Its surface bears a $500 \times 500 \mathrm{~mm}$ cut, inside which the vibration plate is inserted. Four support aluminum tabs, located at each corner of the cut, allow the vibration plate to rest on the frame with minimal contact. The frame is placed on top of a custom-made table, equipped with four waterjet-cut steel legs that can be adjusted in length, so as to allow for the tuning of the light projection's height. The contact with the table is realized by three height adjustment screws, which are used to calibrate the frame's (and thus the vibration plate's) horizontal inclination. Illumination is provided by a 1,000 lumen LED lamp (Cree XM-L T6), placed in a 3D printed case attached to the frame's surface.

The vibration system's internal structure (visible in Fig. 18) is composed of an assemblage of three materials: a $30 \mathrm{~mm}$ thick extruded polystyrene board, a $10 \mathrm{~mm}$ thick foam board, and a $1 \mathrm{~mm}$ thick aluminum covering on top. The vibration is provided by four surface transducers secured to the bottom face of the polystyrene board by threaded rods embedded in the material. We used commercial transducers (Visaton EX $60 \mathrm{~S}$ ) designed for sound and music applications, which we fed an 80-125 Hz sine wave produced by a Pure Data program running on a Raspberry Pi Linux micro-computer, processed through a $25 \mathrm{~W}$ Hi-Fi amplifier (Dynavox CS-PA1). Because of their location, the transducers are not visible when the setup is observed from a normal viewpoint. For aesthetic reasons, the polystyrene board's and foam board's side faces are also hidden by a square-shaped aluminum 'fence,' attached to the frame with 3D printed connectors, and rising $10 \mathrm{~mm}$ above the vibration system's top surface. This fence performs the additional function of preventing the grains from falling onto the frame when moving.

Figure 19 shows an exploded view of the grain design. The assembly starting point is a $20 \mathrm{~mm}$ diameter 3D printed PLA disk, the bottom side of which includes an 


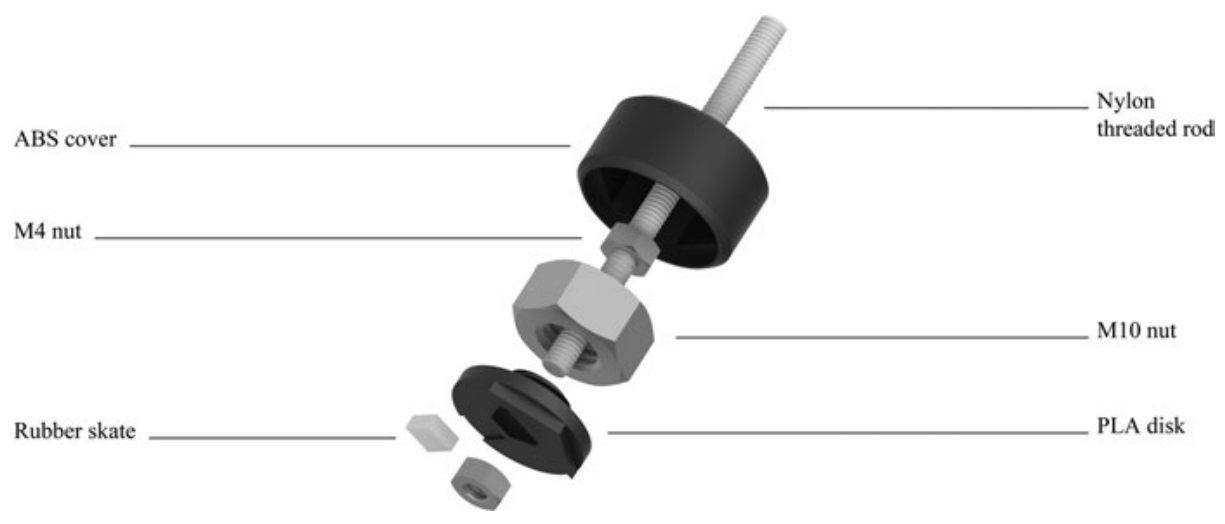

Fig. 19: Exploded view of Manoeuvres' grain design. (c) lanis Lallemand.

extruded triangular profile which constitutes one of the grain's legs. The second leg consists in a $5 \times 5 \mathrm{~mm}$ skate, cut from a $1 \mathrm{~mm}$ thick rubber vibration damping pad ( $3 \mathrm{M}$ 0500.54 G.70). As in EC2M's original experiment, the different mechanical responses exhibited by the two legs' materials (PLA and rubber) induce a polar asymmetry that allows the grain to achieve directed motion; as we realized soon, however, this behavior can only be observed if the grain has a higher mass than given by its PLA disk alone. To provide the requisite mass, we thus designed a $10 \mathrm{~mm}$ diameter threaded cylinder on the top side of the disk, which allows securing an M10 nut to the grain.

A crucial feature of the grain design is the vertical rod, required by Manoeuvres' light projection concept. As the rod has to rise by about $50 \mathrm{~mm}$ over the PLA base to create large enough shadows, the structure becomes prone to the development of energy-dissipating vibrations, which can harm the grains' motion. This effect can be limited by reducing the mass of the vertical rod. We thus used a $5 \mathrm{~mm}$ diameter, $50 \mathrm{~mm}$ long nylon threaded rod, inserted through the PLA disk and secured to it by two M4 nuts, which help keep the rod in a perfectly straight position - a requirement otherwise difficult to meet given the grain's thin profile. A hollow cylindrical ABS cover completes the design by hiding the grain's internal components, resulting in a simpler external appearance.

\subsection{Results and Discussion}

Manoeuvres was first presented to the public as part of a performance organized at the Espace Pierre-Gilles de Gennes in Paris, on June 23, 2016, following the completion of the project's first working prototype. After a short discussion of our system's relationship with EC2M's original experiment, viewers were invited to freely experiment its behavior and engage with the grains' collective motion. The project was then exhibited at the Gaîté lyrique, in Paris, as part of our PhD defense's exhibition, 
which ran from December 2 to 5, 2017. These two contexts, differing both in terms of duration and settings - the Gaîté lyrique exhibition featured other works and a specially designed scenography - provided two complementary testing scenarios of the
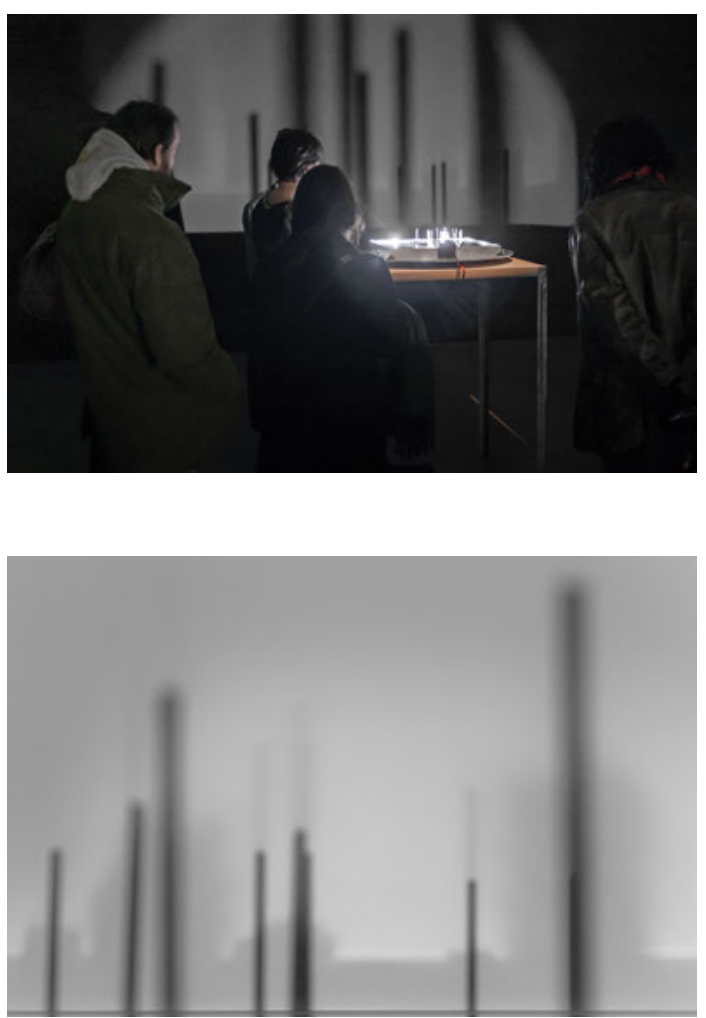

Fig. 20: View of the exhibition at the Gaîté lyrique, Paris, December 2-5, 2017. () Jean-Marc Lallemand (reproduced with authorization).

Fig. 21: A light projection produced by Manoeuvres. (C) lanis Lallemand.

project's concept and design implementation. Figure 20 shows a view of the Gaîté lyrique exhibition, and Fig. 21 presents a light projection produced by the system. Although Manoeuvres' setup, by its analog nature, follows a different approach than explored in Unspecified Clay, the project may also be envisioned as an experiment in designing feedback mechanisms, for the purpose of enabling reciprocal interactions between a production apparatus and its material environment: just as Unspecified Clay's retroactive algorithms allowed the system to build on emergent external conditions, so could the material principles of motion built into Manoeuvres negotiate the emergent behavior of the public. During the performance at the Espace Pierre-Gilles de Gennes, for instance, a surprisingly efficient (albeit rather erratic) motion mechanism was experimented by some viewers, who discovered that the agents could still 'walk' when laid on their side, their shadow-casting rod touching the vibration plate - an unplanned configuration which was easily 
supported by our system. Far from being anecdotal, this example illustrates the intrinsic playfulness and discoverability built into the project, by means of its analog design principles. Such qualities may motivate the use of analog design methods as an alternative to traditional, digitally oriented approaches to interaction design, which have in the past few years tied our existences to an increasing amount of opaque, black box like devices [Haque 2007, p. 60] - from our phones to the growing population of 'smart' assistants inhabiting our homes.

On another level, experimenting with Manoeuvres led us to envision the very notion of material activity from a new perspective. We indeed observed that the system's self-organizing behavior had the capacity to permeate the organization of the public itself: groups of viewers would form, structured both by direct interactions with the device, and by indirect, interpublic interactions - such as, for instance, the commenting of light projection patterns created by others, or the discussion of the grains' motion principles, experienced by observing other viewers play with the system. Manoeuvres' active 'grain material' appeared to us, in this respect, as equally structured and structuring, as the reach of its performances extended up to the human crowd. Such an observation ultimately calls for an understanding of material activity as a true form of agency within the creative project, in a stronger sense than usually envisioned in design-oriented applications of 'smart' or responsive materials.

\section{Conclusion}

This chapter has introduced two complementary approaches for the exploration of material activity within a research-oriented, digital design practice. The discussed projects, Unspecified Clay and Manoeuvres, follow our initial call for design processes achieving a form of openness toward material behavior, by adopting a performative, rather than representational approach to form making.

In Unspecified Clay, digital techniques are mobilized to set up a closed feedback loop between a robotic 3D printing system and the physical behavior of clay, letting form emerge from this reciprocal process of interaction as it unfolds over time. Beyond the setting up of the experiment's technical apparatus, the design approach focuses here primarily on the creation of computational processes, seeking to channel the interplay of robotic, digital, and physical behavior by means of implicit methods rather than geometric prescription.

Manoeuvres, based on an existing experiment by Olivier Dauchot and the EC2M research team, investigates the concept of active matter through the question of collective motion - an object of ever-increasing attention in the physics community since the publication of Vicsek et al.'s theoretical behavior model in 1995. The project takes the form of an interactive production system, whose output - a light 
projection - is obtained through the collective motion of active grains, following a behavior-to-form translation process inspired by the digital method of multi-agent systems. Derived from EC2M's initial experiment, Manoeuvres' design is fundamentally driven by an openness to material behavior: in an alternative approach to sensor and motor-based approaches, collective motion is here achieved by tapping into the physical qualities of a specially designed material unit (the grain), which is left to interact, without any form of programmed control, with the behavior of its fellow partners.

These two instances of open-design processes ultimately illustrate two contrasting traits of digital design research's relationship with the notion of active matter, of which we have mentioned several other examples throughout this chapter. On the one hand, more digital processes today implement sensing and data analysis mechanisms (such as the 3D scanning and feedback procedures built into our Unspecified Clay project) that allow them to operate in 'greater proximity' with the physical world. Instead of attempting to fully predict the properties of physical materials through digital simulations, new production strategies instead implement feedback mechanisms into manufacturing systems, enabling the continuous update of computational models with real-world data. On the other hand, digital designers are increasingly drawn toward the production of analog components, transposing methods and ideas from the digital world into the new landscapes of physical behavior opened by today's active materials.

While these two approaches may at first seem to embody divergent research trajectories - the first of them focusing on the expansion of digital systems' capacities, and the latter advocating for the development of new analog production methods what is at stake in both cases is an evolution of design practice toward a performative - rather than representational - approach to materiality. In contrast to representational design approaches, which intend to geometrically define form in its totality before physical realization, the two case studies discussed in this chapter demonstrate how one can approach the production of form as a dynamic process, happening in the 'here and now' of the physical mobilization of material performances. As materials become active participants in the definition of form, designers invest increasingly in the development of dynamic production systems, often based on similar ideas regardless of their digital or analog nature - such as the notion of agent-based systems, developed by both Unspecified Clay and Manoeuvres projects. Far from being antagonists, analog and digital approaches thus appear as complementary directions for the investigation of performative design methodologies and processes in the era of active materials. 


\section{Bibliography}

Alberti LB. On the Art of Building in Ten Books. Trans. Rykwert J, Leach N, Tavernor R. Cambridge, MIT Press, 1988.

Anderson C. Makers: The New Industrial Revolution. New York, Crown Business, 2012.

Augugliaro F, Lupashin S, Hamer M, et al. The Flight Assembled Architecture Installation: Cooperative Construction with Flying Machines. IEEE Control Systems Magazine 2014, 34 (4), 46-64, DOI: 10.1109/MCS.2014.2320359.

Bézier P. A View of the CAD/CAM Development Period. In: Blomenthal J, Barnhill RE, Barsky BA et al. Graphics Remembrances. IEEE Annals of the History of Computing 1998, 20 (2), 35-51, here 37-40.

Bianchini S, Verhagen E, eds. Practicable: From Participation to Interaction in Contemporary Art. Cambridge, MIT Press, 2016.

Boutinet JP. Psychologie des conduites à projet. Paris, PUF, 1993.

Boutinet JP. Projet. In: Barus-Michel J, Enriquez E, Lévy A, eds. Vocabulaire de psychosociologie. Toulouse, Érès, 2002, 222-230.

Carpo M. The Alphabet and the Algorithm. Cambridge, MIT Press, 2011.

Colletti M. An Example of [En]coding Neo Materialism: ProtoRobotic FOAMing. In: Werner LC, ed. [En]Coding Architecture. Pittsburgh, Carnegie Mellon University, School of Architecture, 2013, 57-65.

Damisch H. The Origin of Perspective. Cambridge, MIT Press, 1995.

Del Campo M, Fure A, McGee W, Manninger S, Flexer A. Autonomous Tectonics: A Research into Emergent Robotic Construction Methods. In: Gengnagel C, Kilian A, Nembrini J, eds. Rethinking Prototyping: Proceedings of the Design Modelling Symposium Berlin 2013. Berlin, Universität der Künste, 2013, 417-432.

DeLanda M. Philosophies of Design: The Case of Modeling Software. In: Salazar J, ed. Verb Processing. Barcelona, Actar, 2002, 130-143.

Deseigne J, Dauchot O, Chaté H. Collective Motion of Vibrated Polar Disks. Physical Review Letters 2010, 105 (9), 098001, DOI: 10.1103/PhysRevLett.105.098001.

Doerstelmann M, Knippers J, Koslowski V, et al. ICD/ITKE Research Pavilion 2014-15: Fibre Placement on a Pneumatic Body Based on a Water Spider Web. Architectural Design 2015, 85 (5), 60-65, DOI: 10.1002/ad.1955.

Dörfler K, Ernst S, Piškorec L, et al. Remote Material Deposition: Exploration of Reciprocal Digital and Material Computational Capacities. In: Voyatzaki M, ed. What's the Matter: Materiality and Materialism at the Age of Computation. Barcelona, ETSAB - UPC, 2014, 361-377.

Evans R. Translations from Drawing to Building. In: Evans R. Translations from Drawing to Building and Other Essays. Cambridge, MIT Press, 1997, 153-193.

Frampton K. Studies in Tectonic Culture: The Poetics of Construction in Nineteenth and Twentieth Century Architecture. Cambridge, MIT Press, 1995.

Frampton K, Allen S, Foster H. A Conversation with Kenneth Frampton. October 2003, 106, 35-58, DOI: $10.1162 / 016228703322791016$.

Garcia MJ, Retsin G. Design Methods for Large Scale Printing. In: Martens B, Wurzer G, Grasl T, Lorenz WE, Schaffranek R, eds. Real Time: Proceedings of the 33rd eCAADe Conference.

Vol. 2. Vienna, Vienna University of Technology, 2015, 331-339.

Glaeser L. The Work of Frei Otto. New York, Museum of Modern Art, 1972.

Goodman N. Languages of Art: An Approach to a Theory of Symbols. Indianapolis, Bobbs-Merrill, 1968.

Haque U. The Architectural Relevance of Gordon Pask. Architectural Design 2007, 77 (4), 54-61. 
Huerta S. Structural Design in the Work of Gaudí. Architectural Science Review 2006, 49 (4), 324-339, DOI: 10.3763/asre.2006.4943.

Ingold T. Making: Anthropology, Archaeology, Art and Architecture. London, Routledge, 2013.

Jack MA. The Accademia del Disegno in Late Renaissance Florence. The Sixteenth Century Journal 1976, 7 (2), 3-20, DOI: 10.2307/2539556.

Johns RL. Augmented Materiality: Modelling with Material Indeterminacy. In: Gramazio F, Kohler M, Langenberg S, eds. Fabricate: Negotiating Design and Making. Zurich, gta Verlag, 2014, 216-223.

Kadic M, Bückmann T, Schittny R, Wegener M. Metamaterials Beyond Electromagnetism. Reports on Progress in Physics 2013, 76 (12), 126501, DOI: 10.1088/0034-4885/76/12/126501.

Kensek KM. Building Information Modeling. London, Routledge, 2014.

King R. Brunelleschi's Dome: How a Renaissance Genius Reinvented Architecture. New York, Walker \& Company, 2000.

Le Corbusier PJ. CEuvre Complète. Vol. 5. 1946-1952. Boesinger W., ed. Zurich, Les Éditions D'Architecture, 1991.

Lynn G. Architectural Curvilinearity: The Folded, the Pliant and the Supple. Architectural Design 1993, 102 (8), 15.

Lynn G. Animate Form. New York, Princeton Architectural Press, 1999.

Menges A. Material Computation: Higher Integration in Morphogenetic Design. Architectural Design 2012, 82 (2), 14-21, DOI: 10.1002/ad.1374.

Menges A. Fusing the Computational and the Physical: Towards a Novel Material Culture. Architectural Design 2015, 85 (8), 9-15, DOI: 10.1002/ad.1947.

Menges A, Reichert S. Performative Wood: Physically Programming the Responsive Architecture of the HygroScope and HygroSkin Projects. Architectural Design 2015, 85 (5), 66-73, DOI: 10.1002/ad.1956.

Mitchell WJ. Antitectonics: The Poetics of Virtuality. In: Beckmann J, ed. Virtual Dimension: Architecture, Representation, and Crash Culture. New York, Princeton Architectural Press, 1998, 205-217.

Morel P. Computation or Revolution. Architectural Design 2014, 84 (3), 76-87, DOI: 10.1002/ad.1761. Negroponte N. Being Digital. New York, Alfred A. Knopf, 1995.

Oxman N. Material-Based Design Computation. PhD thesis. Cambridge, MIT, 2010.

Picon A. Architecture and the Virtual: Towards a New Materiality. Praxis 2004, 6, 114-121.

Popkin G. The Physics of Life. Nature News 2016, 529 (7584), 16-18, DOI: 10.1038/529016a.

Rajkumar R, Lee I, Sha L, Stankovic J. Cyber-Physical Systems: The Next Computing Revolution. In: Proceedings of the 47th Design Automation Conference. ACM, 2010, 731-736.

Retsin G, Garcia MJ. Discrete Computational Methods for Robotic Additive Manufacturing: Combinatorial Toolpaths. In: Posthuman Frontiers: Data, Designers, and Cognitive Machines. Proceedings of the 36th Annual Conference of the Association for Computer Aided Design in Architecture (ACADIA). Ann Arbor, University of Michigan Taubman College, 2016, 332-341.

Reynolds CW. Flocks, Herds and Schools: A Distributed Behavioral Model. ACM SIGGRAPH Computer Graphics 1987, 21 (4), 25-34, DOI: 10.1145/37401.37406.

Rubenstein M, Ahler C, Hoff N, Cabrera A, Nagpal R. Kilobot: A Low Cost Robot With Scalable Operations Designed for Collective Behaviors. Robotics and Autonomous Systems 2014, 62 (7), 966-975, DOI: 10.1016/j.robot.2013.08.006.

Schäffner W. The Design Turn: Una Revolución Científica en el Espíritu Del Diseño. Kepes 2010, 7 (6), 61-75.

Schwinn T, Menges A. Fabrication Agency: Landesgartenschau Exhibition Hall. Architectural Design 2015, 85 (5), 92-99, DOI: 10.1002/ad.1960. 
Serlio S. Il terzo libro di Sabastiano Serlio bolognese, nel qual si figurano, e descrivono le antiquita di Roma e le altre che sono in Italia, e fuori d'Italia. Venice, Francesco Marcolini da Forlì, 1540.

Snooks R. Volatile Formation. Log 2012, 25, 55-62.

Snooks R, Jahn G. Stigmergic Accretion. In: Reinhardt D, Saunders R, ed. Robotic Fabrication in Architecture, Art and Design 2016. Cham, Springer, 2016, 398-409.

Toffler A. Future Shock. New York, Random House, 1970.

Vasari G. The Lives of the Artists. Trans. Bondanella JC, Bondanella P. Oxford, Oxford University Press, 1998.

Vial S. De la spécificité du projet en design: une démonstration. Communication et Organisation 2014, 46, 17-32, DOI: 10.4000/communicationorganisation.4699.

Vicsek T, Czirók A, Ben-Jacob E, Cohen I, Shochet O. Novel Type of Phase Transition in a System of Self-Driven Particles. Physical Review Letters 1995, 75 (6), 1226-1229, DOI: 10.1103/ PhysRevLett.75.1226.

Witt A. Design Hacking: The Machinery of Visual Combinatorics. Log 2011, 23, 17-25.

Zhang Z. Microsoft Kinect Sensor and its Effect. IEEE Multimedia 2012, 19 (2), 4-10, DOI: 10.1109/ MMUL.2012.24.

Ianis Lallemand is a Paris-based designer, researcher, and educator whose work is situated at the intersection of computation, generative design, and digital manufacturing. He is an assistant professor at the École supérieure d'Arts et de Design, Tours Anger Le Mans (TALM), an associated researcher in the Reflective Interaction group at École nationale supérieure des Arts Décoratifs (EnsAD) Paris, and a Co-de-iT member. He received his PhD in design from Paris Sciences et Lettres University (PSL)/EnsAD Paris in 2018. For further information: https://www.ianislallemand.com/. 
